\title{
Implementation of the National
}

Desalination and Water Purification

Technology Roadmap:

Structuring and Directing the

Development of Water Supply Solutions

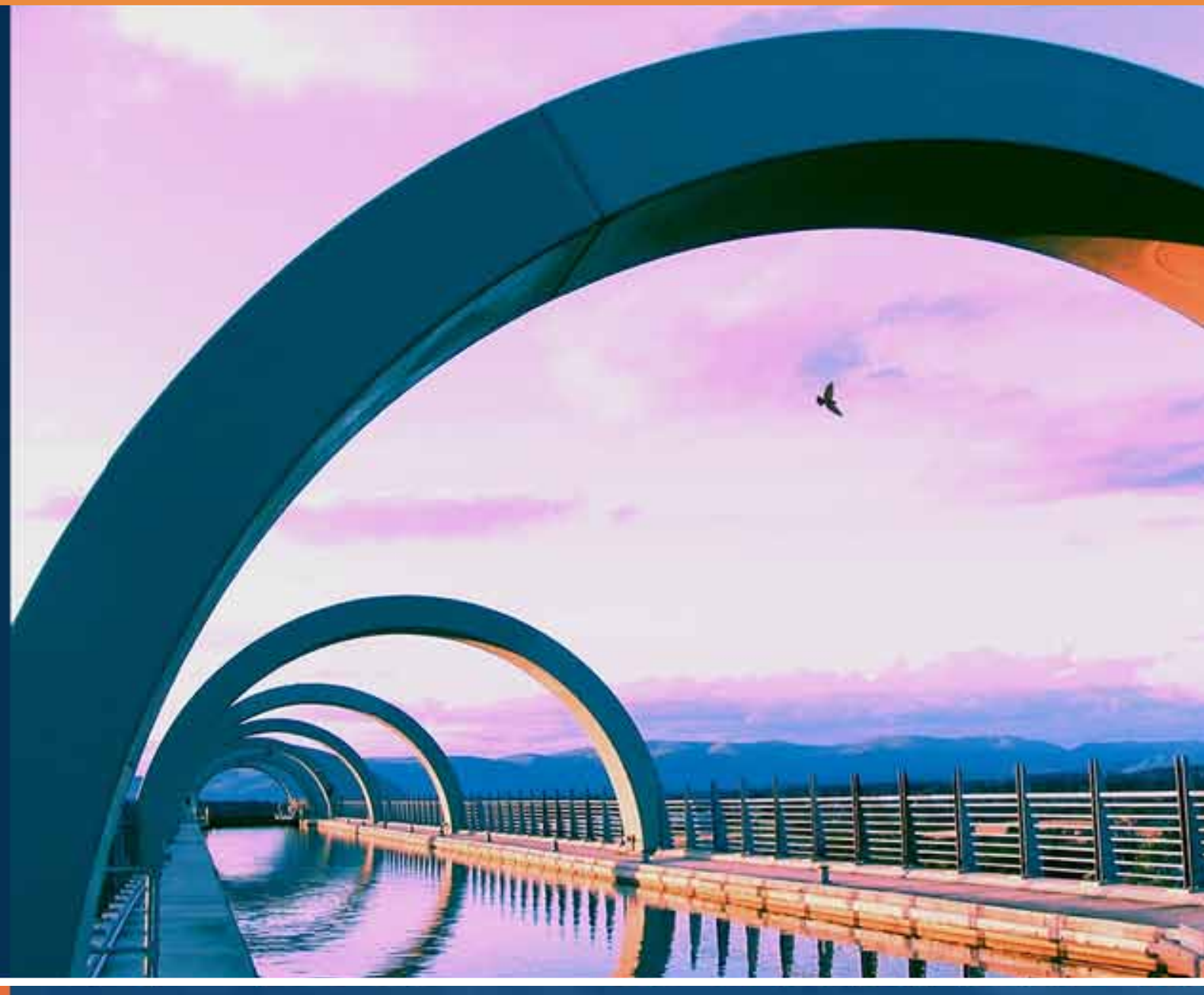

W A T E R

RESEARCH

W/ATEREUSE

F U UNDATION- 


\section{About the Cover}

This document, Implementation of the National Desalination and Water Purification Technology Roadmap: Structuring and Directing the Development of Water Supply Solutions, builds from the work that created the original Desalination and Water Purification Technology Roadmap.

The Roadmap cover image of a waterfall captures the essence of the original document - a free-flowing cascade of research ideas. The Falkirk Wheel aqueduct on this cover captures the essence of the Implementation document-structure that harnesses, defines, and directs those research ideas.

The process used to create the Implementation document places structure around the Roadmap's cascade of ideas. By clarifying the problems to be addressed, identifying the objectives of the work, and presenting possible approaches to meeting the objectives, the Implementation document provides direction to the nation's desalination and water purification research enterprise.

Sandia is a multiprogram laboratory operated by Sandia Corporation, a Lockheed Martin Company, for the United States Department of Energy's National Nuclear Security Administration under contract DE-AC04-94AL85000.

SAND No. SAND2006-3729P
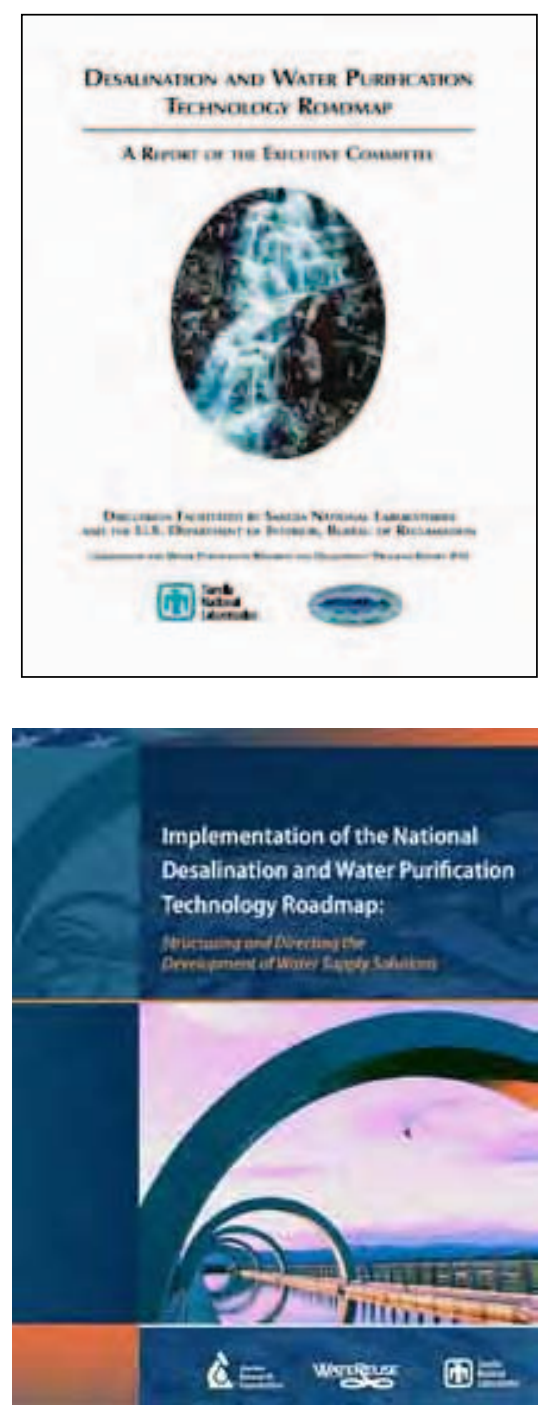

On the cover:

The aqueduct leading to the Falkirk Wheel, Scotland. (C) Alan Bilsborough 


\section{FOREWORD}

Recognizing that our Nation is faced with significant challenges in meeting our future needs for water, Congress requested a desalination technology and implementation plan in the spring of 2002 .

"...The Committee recognizes that effective desalination cost reduction is the key to wider use of desalination for improving the quality of life in water scarce regions. The Secretary of the Interior shall consult with the Secretary of Energy and the Director of the Sandia National Laboratories in the development of the technology and implementation plan." [2002 Energy and Water Development Appropriation Bill]

Authorized by Congress, the Bureau of Reclamation and Sandia National Laboratories initiated a roadmapping effort and brought dozens of experts together from across industry, government, universities, water utilities, and the national laboratories to create a technology progress plan for desalination research. This effort, entitled Desalination and Water Purification Technology Roadmap, or Roadmap, was published in the spring of 2003 and presents a summary of the water supply challenges facing the United States, as well as recommendations for a coordinated national desalination research agenda to meet these challenges.

As the Roadmap was in the process of being completed, the Bureau of Reclamation, asked the National Research Council (NRC) for an independent review of the Roadmap. The NRC review entitled Review of the Desalination and Water Purification Technology Roadmap was published in 2004. The NRC recommended that (1) current funding levels are insufficient to achieve significant improvements in desalination performance and cost, (2) an effective strategy for implementing the roadmap and a strategic national research agenda needs to be developed, and (3) research activities and results should be communicated through various media and the public should be informed about the benefits, affordability, and environmental considerations of desalination.

In order to address these NRC recommendations, the Bureau of Reclamation, with the support of the Environmental Protection Agency, then asked the NRC to convene the Committee on Advancing Desalination Technology to (1) assess the state of the art in relevant desalination technologies and factors such as cost and implementation challenges, (2) describe reasonable long-term goals for advancing desalination technology, and (3) estimate the funding necessary to support the proposed research agenda as well as to identify appropriate roles for governmental and non-governmental entities. This was done with the goal of building upon the Roadmap. The Committee published their results in early 2008 in a document entitled Desalination: A National Perspective. The Committee defined a strategic national research agenda with two overarching strategic goals: (1) understand and minimize the environmental impacts of desalination and (2) develop approaches to lower the financial cost of desalination so that it is an attractive option where traditional sources of water are inadequate to meet water 
needs. The Committee recommended (1) a coordinated strategic plan should be developed to ensure that future federal investments are integrated and prioritized and address the two overarching strategic goals, (2) environmental research should be emphasized when implementing the research agenda, (3) funding should be directed toward research topics that make improvements against benchmarks set by the best current technologies in desalination, and (4) request for proposals should be widely disseminated to meet the goals of the research agenda.

In a parallel effort, starting in early 2004, the Bureau of Reclamation, Sandia National Laboratories, the Water Research Foundation (formerly known as AWWA Research Foundation or AwwaRF), and the WaterReuse Foundation began work to develop a follow on implementation strategy for the original roadmap. The Implementation of the National Desalination and Water Purification Technology Roadmap (this document) was developed to chart the path forward for implementing the original Desalination and Water Purification Technology Roadmap and to describe the needed desalination research in greater detail. Once again, the team relied upon the contributions of dozens of experts from industry, academia, government, and the water utilities brought together in a series of workshops to decide how best to implement the recommendations of the first roadmap and to identify high-impact and non-replicative research to hasten the rate for the development and implementation of new desalination technologies to meet our Nation's growing water needs. The details of this effort and its recommendations and conclusions are described in the pages that follow.

Mark J. Rigali

Manager, Geochemistry Department

Water Treatment Lead for the Sandia Water Initiative 


\section{Contents}

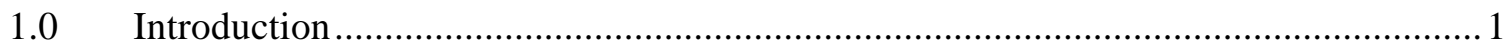

2.0 R\&D Implementation: Development Process and Organization ................................... 3

$2.1 \quad$ The Stakeholders Workshop …………………..................................................

2.2 The Source Waters/User Needs Meeting ........................................................... 4

2.3 The Water Innovation Symposium ………………...........................................

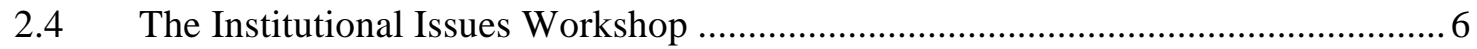

3.0 National Research Area: Membrane Technologies ......................................................

$3.1 \quad$ Research Agenda: Pretreatment ................................................................

3.2 Research Agenda: Membrane Performance/Properties .......................................... 9

3.3 Research Agenda: Fouling .......................................................................

$3.4 \quad$ Research Agenda: Post-Treatment.................................................................. 11

3.5 Research Agenda: Operations..................................................................... 12

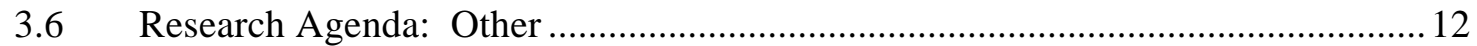

4.0 National Research Area: Alternative Technologies..................................................15

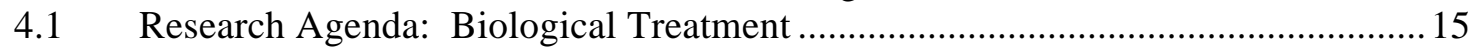

4.2 Research Agenda: Hybrid Systems............................................................... 16

4.3 Research Agenda: Alternative Membranes …………….................................... 17

4.4 Research Agenda: Offshore Desalination ....................................................... 19

5.0 National Research Area: Concentrate Management Technologies.............................22

$5.1 \quad$ Research Agenda: Disposal, Fundamental Research............................................22

5.2 Research Agenda: Disposal, Applied Research.................................................24

5.3 Research Agenda: Beneficial Use, Fundamental Research ..................................25

5.4 Research Agenda: Beneficial Use, Applied Research ..........................................26

5.5 Research Agenda: Energy Consumption and Recovery .......................................27

6.0 National Research Area: Institutional Issues .........................................................29

6.1 Research Agenda: Energy Cost Reduction .......................................................... 30

6.2 Research Agenda: Environmental Considerations ................................................30

6.3 Research Agenda: Alternative Water Supplies and the Role of Desalination ........31

6.4 Research Agenda: Regulatory/Policy Considerations ............................................33

6.5 Research Agenda: Outreach to Water Professionals ................................................35

6.6 Research Agenda: Improving the Understanding of the Technology ………..........36

6.7 Research Agenda: Understanding the Economics of Desalination .........................37

6.8 Research Agenda: Consumer Outreach .................................................................. 37

6.9 Research Agenda: Determine Benefits of Desalination ....................................... 38

6.10 Research Agenda: Synthesize State-of-the-Science …………............................ 38

Appendix A: Meeting Participants ....................................................................

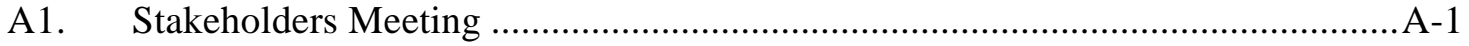

A2. Source Waters/User Needs Meeting ..............................................................

A3. The Water Innovation Symposium .............................................................A-2

A4. The Institutional Issues Workshop …………………..................................

Appendix B: Findings from The Source Waters/User Needs Meeting ............................. B-1

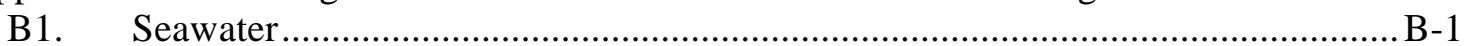

B2. Brackish Waters (Surface and Ground) ………………………………..........

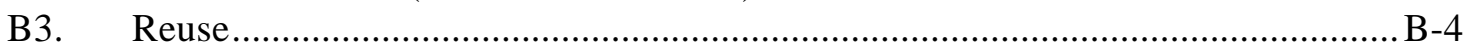

B4. Cross-Cutting Needs .................................................................................

B5. Summary of Institutional Issues ................................................................. B-6 


\subsection{INTRODUCTION}

In the United States, economic growth increasingly requires that greater volumes of freshwater be made available for new users, yet supplies of freshwater are already allocated to existing users. Currently, water for new users is made available through re-allocation of existing water supplies - for example, by cities purchasing agricultural water rights. Water may also be made available through conservation efforts and, in some locales, through the development of "new" water from non-traditional sources such as the oceans, deep aquifer brackish groundwater, and water reuse.

Developing "new" water from non-traditional sources relies primarily on membrane filtration (e.g., reverse osmosis) and to a lesser extent distillation. Both are technology-intensive processes whose future depends on the development of, respectively, better membranes and more efficient heat transfer approaches. Membrane filtration in particular carries with it weighty pre- and post-treatment concerns: How to prevent the formation of filter-clogging inorganic and biologic scales? How to dispose of residual concentrated brines? How to chemically stabilize the water that is produced?

Water development in the $20^{\text {th }}$ century largely involved the physical collection and transfer of freshwater by dams and aqueducts. Because of tightening supplies and public resistance to further dam building, water development in the $21^{\text {st }}$ century will increasingly rely on creating or reclaiming water from nontraditional sources by membrane filtration and other desalination processes. Since

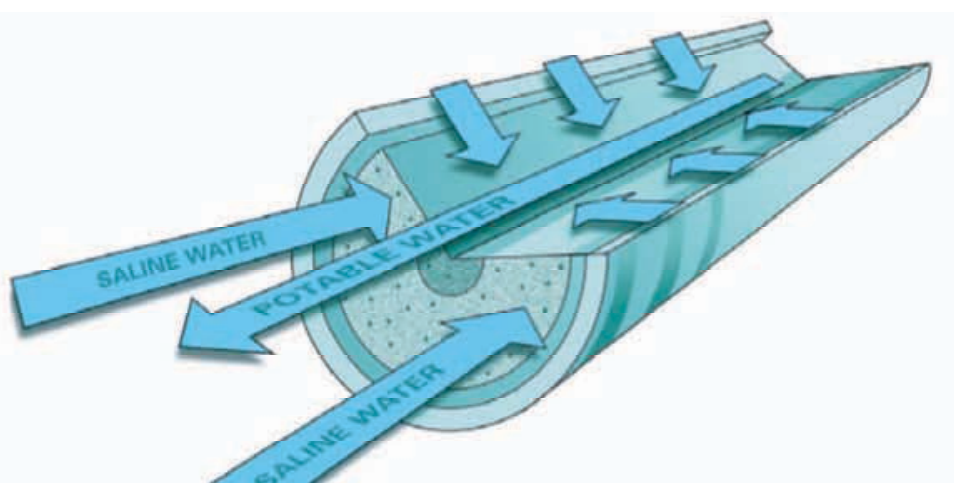
Water Purification by Reverse Osmosis (pubs.usgs.gov/ fs/fs075-03/)
Filtration Membrane Element

the latter are tied so strongly

to technology, the absolute volume of new water produced in the United States in the $21^{\text {st }}$ century will likely reflect the extent of new research and development investment in desalination.

This has happened before. In the 1950s and 1960s, the U.S. government invested a total of roughly $\$ 900$ million (in 1985 dollars) in desalination research conducted through the Office of Saline Water in the Department of the Interior. Reverse osmosis (RO) desalination is one of the notable inventions that resulted from this federal investment: RO is presently a $\$ 2$ billion per year global market, and the technology is used to produce six billion gallons of water per day. Increasing the availability of new water will likely require a renewed national commitment to desalination research and development.

The objective of the National Desalination and Water Purification Roadmap and this Implementation document is to establish a coordinated national desalination research agenda 
that identifies high-impact and non-replicative research, thereby hastening the rate at which desalination technologies are developed and implemented to provide new water.

This effort would not have reached a successful conclusion without the help and support of a host of workshop participants to whom we are profoundly grateful. These individuals are identified in Appendix A. Tom Arn and Hy Pomerance of Red Oak Consulting were instrumental in facilitating the workshops. Zachary Dorsey of the WateReuse Foundation produced the individual workshop reports. Conrad Mulligan of McNeil Technologies has played a critical role in organizing the outputs of the workshops and producing this document.

Patrick V. Brady, editor 


\subsection{R\&D IMPLEMENTATION: DEVELOPMENT PROCESS AND ORGANIZATION}

The Congressionally mandated Desalination and Water Purification Technology Roadmap was created in 2003 to map out a long-term research strategy for desalination and other water purification technologies. In 2004, a decision was made to implement the findings and provisions of the Roadmap - specifically to describe in greater detail needed research-under the auspices of the AWWA Research Foundation, Sandia National Laboratories, and the WateReuse Foundation.

Created in response to a desire for a unified approach to advancing the technology of desalination and water purification, this Implementation document has two objectives: Hasten the rate of technological advance and reduce the cost of desalination technologies. This will be accomplished by cultivating and coordinating multiple research efforts at a national level with the goal of meeting current and projected "real-world," user-generated needs. This document complements the Desalination and Water Purification Technologies Roadmap but differs from it by identifying specific research projects critical to the growth of desalination.

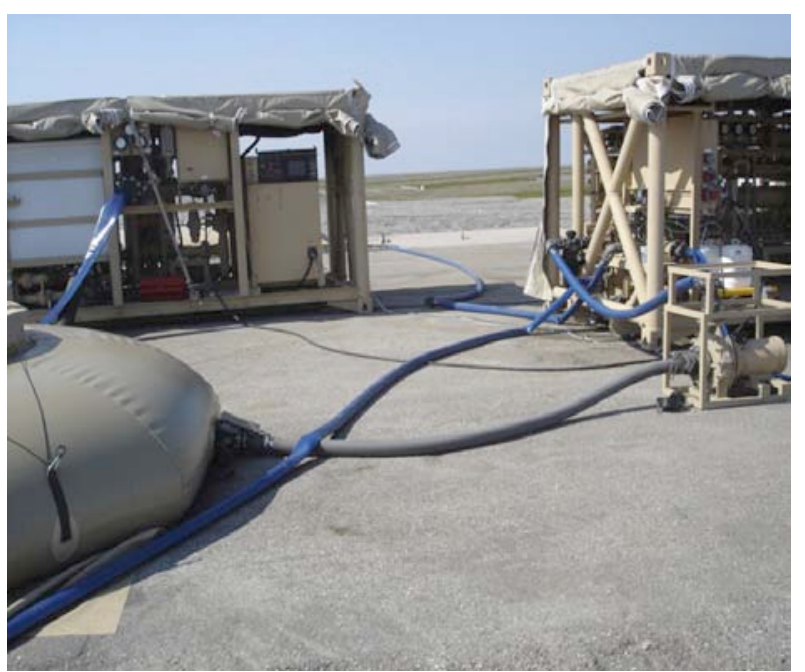

The Expeditionary Unit Water Purification (EUWP) Unit, developed by the Office of Naval Research, produces up to 100,000 gallons of water per day through ultrafiltration and reverse osmosis and was used in the aftermath of Hurricane Katrina.

Four meetings were convened to create the Implementation document:

1. A Stakeholders Workshop to refine the vision of the Roadmap and define the scope of technical and institutional issues meetings.

2. A Source Waters/User Needs Workshop to identify and elucidate source waterspecific user needs today and in the future.

3. A Water Innovation Symposium to generate technology-specific research and development statements that will meet these needs.

4. An Institutional Issues Workshop to examine and map the legal and regulatory obstacles to technological change that may inhibit the meeting of user needs. 


\subsection{The Stakeholders Workshop \\ Goal}

Participants at the Stakeholders Workshop (held in November 2004 in San Diego, California) were convened to assist in determining how to implement the Desalination and Water Purification Technologies Roadmap.

In the Stakeholders Meeting, participants were asked to:

- Refine the vision with respect to Roadmap implementation; and

- Delineate the scope of technical workshops being planned.

\section{Attendees}

The Stakeholders Workshop gathered together representatives from more than 20 organizations who are significant stakeholders in desalination and water purification. A list of attendees can be found in Appendix A1.

\section{Outcome}

In pursuit of an Implementation procedure, the stakeholders recommended that five focused workshops be convened to cover the following topics:

- Source Waters (i.e., seawater, brackish, water reuse)

- Membrane Technologies

- Alternative Technologies

- Concentrate Management

- Institutional Issues

This recommendation and framework was adopted, and has been employed to create this Implementation document.

\subsection{The Source Waters/User Needs Meeting Goal}

Attendees of the Source Waters/User Needs Meeting (convened May 2-3, 2005, in Tampa Bay, Florida) were charged to: "Elicit by source water a list of research needs to frame the direction and content of the Water Innovation Symposium meetings."

\section{Process}

Source water-specific research needs were generated in a series of facilitated plenary and breakout working group sessions. The meeting considered three primary source waters-seawater, brackish water (both surface and ground water), and recycled or reused water. Participants were asked at first to brainstorm and record current and projected needs and challenges (e.g., technology needs, failings in our current understanding of the science of desalination and water purification) presented by each type of source water. Attendees were then asked to add detail to these brainstormed lists and to prioritize the research needs.

Participants were asked to think of needs that could be met by either or both evolutionary and revolutionary R\&D activities, products, and processes - participants were not confined to the conventional "box," but encouraged to think of needs that will challenge the Nation's researchers. This approach provided a portfolio of needs across the development spectrum from near-term, product-development activities that are largely the domain of industry to the long- 
term, high-risk/high-payoff basic research that is traditionally the domain of the Federal Government.

\section{Attendees}

The Source Waters/User Needs Meeting brought together 18 individuals selected to be broadly representative of the users of desalination and water purification technologies - system designers, engineering firms, plant owners and operators, and water managers. Also included were research program managers from government and industry.

The Source Waters/User Needs Meeting attendees were chosen for their knowledge of the range of source waters available within the United States_coastal states with access to seawater; inland locales with brackish surface or ground water resources; and areas with an opportunity to reuse a variety of impaired waters (municipal wastewater, water produced along with hydrocarbon extraction activities, industrial effluents, etc.). Attendees are listed in Appendix A2.

\section{Outcome}

Users identified a host of source water-specific research needs, including:

- Seawater desalination research needs: Pretreatment; membrane performance; fouling; energy minimization; post-treatment; and consideration of non-membrane-based desalination processes.

- Brackish water research needs: Concentrate management; pretreatment; source water characterization; and total dissolved solids (TDS) removal (conventional and novel). Concentrate management was identified as the primary research need by users, who called for more research to reduce concentrate volumes; reduce energy costs; provide for beneficial use of salts; and overcome/address institutional barriers.

- Reuse research needs: Sensors/monitoring; contaminant removal; and advanced treatment.

The results of the Source Waters/User Needs Meeting are provided in greater detail in Appendix B.

\subsection{ThE WATER INNOVATION SYMPOSIUM}

\section{Goal}

The Water Innovation Symposium (held October 17-21, 2005, in San Diego, California) was convened to identify and develop individual research thrusts that define the long-term, national research agenda for desalination and water purification technologies.

\section{Process}

The Symposium consisted of three technical workshops, one each on the topics of membrane technologies, alternative technologies, and concentrate management. Each workshop brought together a group of invited technical experts for one and one-half days to develop research project descriptions.

To assist participants in preparation for the Water Innovation Symposium, State-of-the-Science reports were prepared on membrane technologies, alternative technologies, and concentrate management. Each State-of-the-Science report described current technological capabilities and concluded with a discrete list of proposed research needs for the consideration of meeting 
Symposium attendees. These lists were not prescriptive but rather were used as "strawmen" to prompt identification of research areas by the Symposium participants.

\section{Attendees}

The Water Innovation Symposium brought together a diverse group of scientists, engineers, water managers, and government officials, including some of the foremost experts in desalination and water purification. Thirty-one individuals comprised the Membrane Technologies Workgroup; 28 individuals formed the Alternative Technologies Workgroup; and 27 attended the Concentrate Management Workgroup. Participants are listed in Appendix A3.

\section{Outcome}

The information generated during the Water Innovation Symposium forms the basis of this

Implementation document and is presented in Sections 3, 4, and 5 of this document.

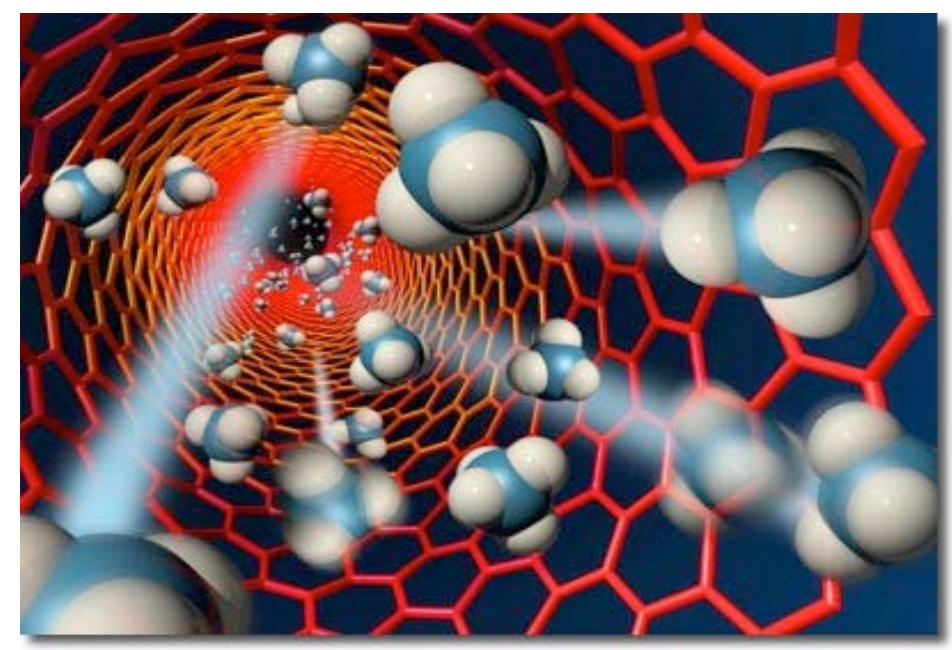

Schematic of methane moving through carbon nanotubes. Similar carbon nanotubes might be used for desalination (http://www.llnl.gov/PAO/news/news_releases/2006/images/me mbrane86x86s.jpg;Scott Dougherty, Lawrence Livermore National Laboratory).

\subsection{THE INSTITUTIONAL ISSUES WORKSHOP Goal}

The Institutional Issues Workshop (held April 17-18, 2006, in San Antonio, Texas) was convened to identify research areas that can overcome the institutional issues that may hinder the development of desalination and water purification technologies.

\section{Process}

The Institutional Issues Workshop employed a process similar to the other workshops. Institutional issues-specific research needs were generated in a series of facilitated plenary and breakout working group sessions.

To assist participants in identifying significant institutional issues, an overview report was prepared that identified a host of institutional issues and their potential impacts, and provided a listing of proposed future research and other efforts whose results could be constructively used to keep these issues from becoming critical barriers to desalination.

\section{Attendees}

The Institutional Issues Workshop convened 32 professionals from environmental issues groups, water utilities and districts, research organizations, State and Federal Government, and academia. Participants are listed in Appendix A4. 


\subsection{NATIONAL RESEARCH AREA: MEMBRANE TECHNOLOGIES}

Membrane-based processes are the dominant technology used in desalination and water purification facilities in the United States, and world-wide represent a large and growing share of the total desalination market. The Membrane Technologies State-of-the-Science report identified a range of research priorities for consideration by participants at the Water Innovation Symposium:

- Improving feedwater recovery

- Pretreatment for RO

- Water quality and forticulture

- Biofilm control and studies on microbial fouling

- Studies on Organic Fouling

- Removal of microbials

- Membrane Bioreactor (MBR) as a Pretreatment for membrane desalination

- Documenting the rejection of emerging contaminants

- Strategies for boron control

- Demonstrations of Energy Recovery Strategies

- Water Quality and Corrosion

- Pretreatment for Electrodialysis Reversal (EDR) Microfiltration(MF) and Ion ExchangeIX)

- Fouling of EDR on Secondary Effluent

Participants considered this list in combination with the research areas generated during the Source Waters/User Needs Meeting to frame six research agendas and associated research projects.

\subsection{Research Agenda: Pretreatment}

Improving the pretreatment of source waters offers significant benefits: Energy savings; minimization of the use of consumables (cartridge filters, chemicals, etc.); and more robust RObased desalination systems that can accommodate and adapt to variations in source waters.

\section{Research Project: Seawater Pretreatment Conditioning Optimization}

- Problem/Need. Chlorine-based pretreatment approaches present a host of challenges:

- Improper conditioning leads to biofouling on pretreatment or RO membranes.

- Chlorination breaks down organics creating more easily assimilable organics that promote biofouling.

- Chlorination leads to formation of disinfection by-products (DBPs) that are not effectively removed by seawater RO membranes.

- Objective. Reduce fouling of pretreatment and RO processes in water treatment facilities to increase throughput, lower maintenance costs, and minimize formation of DBPs to comply with regulations.

- Approach. Model current oxidative conditioning of water to develop alternative pretreatments for conditioning seawater. 
Research Project: Integrated Treatment Approaches for Desalination-Specific Problem Contaminants

- Problem/Need. A number of contaminants (e.g., boron, N-nitrosodimethylamine (NDMA), solvents, some (DBPs) -) do not lend themselves to removal by RO MF or nanofiltration (NF). Research is needed to support integrated treatment techniques (IX, granular activated carbon (GAC), etc.).

- Objective. Develop cost-effective removal techniques that will meet looming water quality targets and will broaden the applicability of membrane filtration.

- Approach. Evaluate and test treatment approaches for problem contaminants.

Research Project: Next-Generation Membrane Systems...Beyond Current Spiral Membrane Systems

- Problem/Need. Current spiral membrane systems are complicated by the need for pretreatment.

- Objective. Reduce complexity and energy requirements associated with pretreatment.

- Approach. Develop alternatives to spiral membrane systems.

Research Project: Mechanistic Understanding and Predictive Modeling of Emerging Contaminant Removal by High-Pressure Membranes in Recycled/Seawater

- Problem/Need. There is increasing concern about the potential adverse effects on public health and the environment caused by trace organic compounds in recycled water (e.g., endocrine-disrupting compounds, personal care products, pharmaceutically active compounds) and in seawater (e.g., algal toxins). There is a need to develop a mechanistic framework that allows prediction of rejection of trace organic compounds by nanofiltration andRO.

- Objective. Understand the efficacy of high-pressure membrane rejection of organic compounds for multiple design and operating conditions.

- Approach. Develop and verify framework/model to describe and predict rejection of trace organic compounds. The framework should consider differences in feedwater quality and design and operating conditions:

- Feedwater quality:

- Recycled: Degree of biological treatment (non-nitrified, nitrified, nitrified/de-nitrified), ion composition

- Seawater: Salinity, ion composition

- Design Conditions: Flux, recovery, feedwater $\mathrm{pH}$, membrane type, temperature

- Operating Conditions: Degree of membrane fouling, membrane age, effect of chemical cleaning

\section{Research Project: Pretreatment Mechanism to Prevent Membrane Biofouling}

- Problem/Need. The controls over biofouling are poorly understood, which limits the effectiveness of pretreatment efforts.

- Objective. Reduce life cycle costs by creating design guidelines for pretreatment systems.

- Approach. Develop process and feedback control mechanisms that lead to design guidelines for pretreatment systems. 


\subsection{Research Agenda: Membrane Performance/Properties}

Differing source waters place differing demands on membrane performance—ocean waters contain boron; brackish waters may change composition over time; and removing contaminants from reuse source waters is complicated by the number and types of contaminants, variability in concentration and time, and changing regulations. Better membranes are needed in all three applications to lower costs and increase reliability.

\section{Research Project: Boron Removal in Seawater Reverse Osmosis}

- Problem/Need. Better information and/or techniques for boron removal during seawater $\mathrm{RO}$ are needed. The results from this research would allow utilities to understand the alternatives available to enhance boron removal.

- Objective. Identify new techniques and evaluate existing alternatives for removing boron during seawater RO.

- Approach. Summarize the existing literature on the chemistry of boron, existing treatments, and identify possible new treatments. Conduct laboratory and/or pilot tests, comparing existing alternatives with potential new ones.

Research Project: Improved Feedwater Recovery for Membrane Desalination

- Problem/Need. Improved feedwater recovery is a desire for all source waters. For brackish water applications, concentrate disposal will be reduced. For all feedwater applications, pretreatment cost and energy use are reduced and capital costs may be reduced. Environmental impacts may also be lowered as entrainment/impingement issues associated with water intake are reduced.

- Objective. Increase feedwater recovery.

- Approach. Investigate the use of improved membranes, soluble salts control (for brackish water), and system design improvements. Research additional secondary recovery strategies such as electro-deionization and selective adsorbents.

\section{Research Project: Spiral Membrane System Configuration Optimization}

- Problem/Need. The hydraulic throughput and performance of existing spiral membrane systems might be optimized through use of modified arrays developed through modeling simulation and pilot testing/verification.

- Objective. Use state-of-the-art technologies to increase hydraulic flow through the same system footprint.

- Approach. Evaluate arrays, vessel configuration, variation in type(s) of membranes, etc. (e.g., staged feeding, modified arrays, varying type of membrane from front to back of system due to differential loadings). Conduct initial evaluation based on modeling and simulation. Follow up with pilot testing/verification at existing pilot plant facilities.

\subsection{Research Agenda: Fouling}

Membrane fouling is one of the most important factors that limits greater use of desalination membranes. As particulate matter and fine suspended solids present in the feedwater reduce the water throughput of the desalination membranes over time, costs rise and uptime drops due to increased maintenance and replacement. Fouling is a challenge facing plants that use all feedwater types. 
Research Project: Organic Fouling-Foulant Characterization and Indices Development: Mechanisms, Modeling, and Real-Time Sensing

- Problem/Need. Although membranes are routinely fouled by organic molecules, it is difficult to predict organic fouling potentials using aggregate organic measurements (i.e., total organic carbon [TOC]) in the feedwater. Some source waters with relatively low TOC $(<1 \mathrm{ppm})$ result in dramatic organic fouling while some waters with high TOC (> $8 \mathrm{mg} / \mathrm{l})$ do not. Current research is focused on identifying and classifying the organic molecules responsible for desalination membrane fouling.

- Objective. Characterize foulants and develop fouling indices.

- Approach. Identify naturally occurring geo- and bio-polymers in seawater. Identify organic fouling control mechanisms and develop real-time sensing tools.

Research Project: Particulate and Other Inorganic Fouling-Foulant Characterization and Indices Development, Mechanisms, Modeling, and Real-Time Sensing

- Problem/Need. Most membrane manufacturers require a silt density index $(\mathrm{SDI})<5$ in the feedwater, but an SDI $<3$ is preferred. However, SDI is a poor predictor of inorganic fouling. Fouling by most inorganic salts is fairly well understood, but inorganic fouling by silica is problematic-it is not as well understood, or easily controlled.

- Objective. Reduce or eliminate fouling so that existing membrane systems can be operated at a higher throughput.

- Approach. Improve fouling indices. Develop improved control techniques for silica and inorganic colloidal materials. Develop realtime sensing tools.

\section{Research Project: Salt Water Biofouling- Foulant Characterization and Indices Development, Mechanisms, Modeling, and Real-Time Sensing}

- Problem/Need. Although turbulent cross-flow is maintained in all desalination membrane systems, bacteria are still capable of adhering to the membrane surface by excreting extracellular polymeric substances (EPS) that create a strong bond to the membrane surface. Biofilms result in decreased membrane permeability in pressure-driven applications and increase electrical resistance in potentialdriven processes, increasing the operation and maintenance cost of desalination.

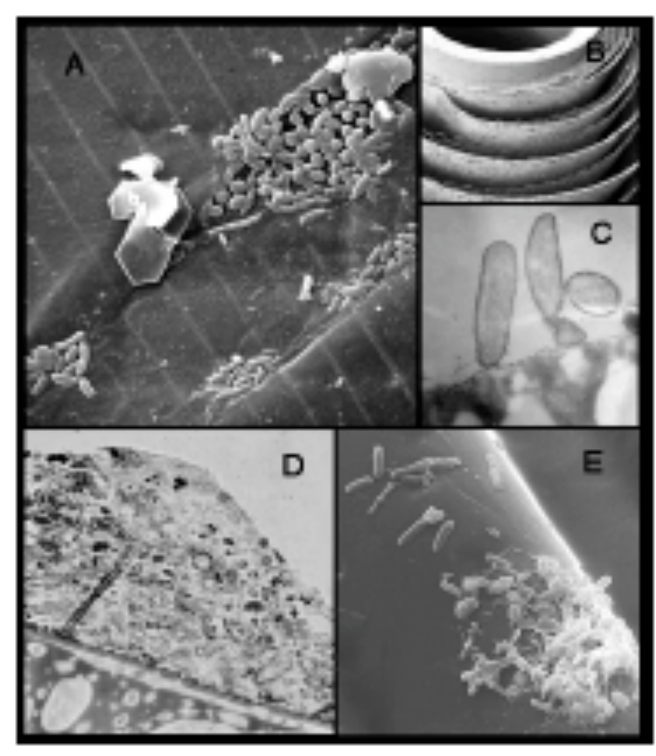

Biological fouling of RO membranes. A: Scanning electron microscope image of bacterial microcolonies formed on the surface of a cellulose acetate RO membrane after approximately three days of operation on pretreated municipal wastewater. B: A biologically fouled spiral-wound RO membrane element. C: Transmission electron micrograph (TEM) of rod-shaped bacteria attached to an RO membrane surface. D: TEM of a mature membrane biofilm. E: Nascent biofilm on permeate surface of a CA membrane.

(From H. Ridgeway, as contained in Trussell, R. Shane, Ph.D., P.E. and R. Rhodes Trussell, Ph.D., P.E., State-of-the-Science Report Number 1, Membrane Desalination Systems. Paper presented at the Technology Innovations Workshop.) 
- Objective. Reduce or eliminate fouling so that existing membrane systems can be operated at a higher throughput.

- Approach. Characterize foulants and develop fouling indices. Identify biofilm forming organisms and their nutrients in seawater. Identify biofouling control mechanisms. Develop real-time sensing tools.

\section{Research Project: Simple Predictor of Membrane Biofouling}

- Problem/Need. Silt density index is an inadequate predictor of membrane biofouling. An alternative is needed that will allow the characterization of source waters using simple measurements.

- Objective. Facilitate operational adjustments (feedback) at the pretreatment process that enable membrane operations/performance adjustments.

- Approach. Develop parameters and correlations/relationships. Develop test method, equipment protocol, quality assurance/quality control processes/tools.
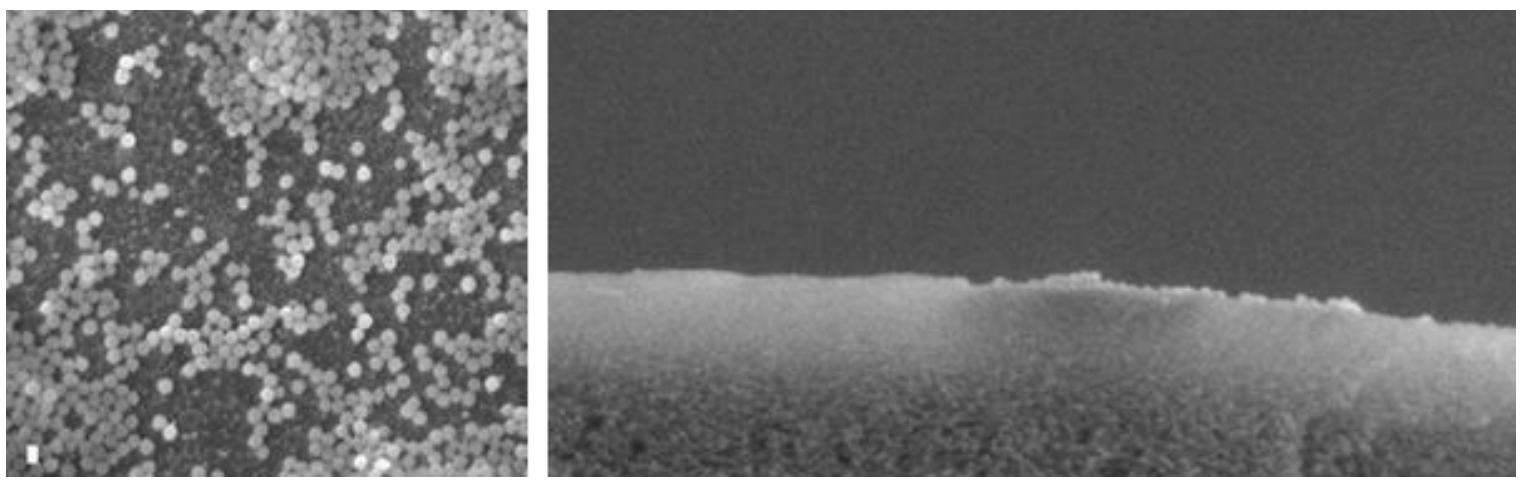

Surface and cross-section views of silica colloid fouling on an NF membrane. Developing an enhanced understanding of silica fouling is necessary to facilitate higher system throughput.

(http://water.usgs.gov/wrri/04grants/Progress\%20Completion\%20Reports/2004OR47B.pdf)

\subsection{Research Agenda: Post-treatment}

As desalination becomes a more important component of municipal and regional water supply, a more complete and fundamental understanding of its impacts will be required. The Source Waters/User Needs Meeting identified the need for industry and regulators to obtain a better understanding of the fundamentals of post-treatment issues including disinfection, stabilization, and blending of waters produced by desalination and purification processes.

\section{Research Project: Post-treatment Stabilization of Desalinated Water}

- Problem/Need. It is essential that customers and regulators accept the quality of water delivered at the point of consumption. Desalinated water presents unique challenges in meeting finished water quality goals (e.g., taste and odor, corrosivity, and issues related to dynamic blending of finished water from different sources). Utilities currently lack clear guidance on meeting these challenges.

- Objective. Substantially enhance acceptability of desalinated water by developing quantitative guidelines linking post-treatment stabilization to water quality goals. 
- Approach. Use U.S. and international case studies to develop and demonstrate posttreatment stabilization guidelines linking water quality targets to customer acceptance of desalinated water.

\subsection{Research Agenda: Operations}

\section{Research Project: Variable Operating Rate Capability Desalination Plants}

- Problem/Need. Membrane-based processes that are operationally flexible (seasonally and from day to day) are needed. Such flexibility offers the potential to lower energy costs by using cheaper off-peak power to make more efficient use of installed power plant capacity that would allow wider use of desalination (particularly in small communities where cost is the limiting factor).

- Objective. Reduce cost of water and increase use of desalination.

- Approach. Investigate methods to maintain membrane performance during non-use (dry vs. wet storage). Develop advanced system designs, including handling startup/shutdowns, off-spec water, etc. Develop advanced process control and monitoring; research disposable (low-cost) membranes.

Research Project: Protocols for Obtaining Pathogen Removal Credits for HighPressure Membranes

- Problem/Need. High-pressure membranes are increasingly used to remove pathogens from recycled water, brackish surface water, and seawater. Currently, regulators are reluctant to award pathogen removal credits because of the absence of established protocols for microbial removal verification, both on new membranes and operating systems. Under the proposed Long Term 2 Enhanced Surface Water Treatment Rule (ESWTR), the Environmental Protection Agency will require both product challenge testing and system direct integrity testing if credit for Cryptosporidium (and Giardia) removal is to be provided. Further, to better manage disinfection by-products and minimize chlorine disinfection, removal credits for all pathogens, including viruses, is needed.

- Objective. Define requirements for and develop methodology and protocol for controlled, challenge testing.

- Approach. Review the existing literature and summarize the state of the art for microbial rejection, challenge studies, microbial surrogates, and existing integrity testing by and for high-pressure membranes. Propose use of 8 " diameter element for challenge testing; compare removals with 2.5", 4", and 16" diameter elements to assess need for challenge testing of multiple diameter elements. Select and evaluate representativeNF, brackish water, and seawater RO elements and RO membranes from a variety of manufacturers. Evaluate efficacy of proposed direct integrity testing at selected pilot- and full-scale facilities.

\subsection{Research Agenda: Other}

\section{Research Project: Water Quality and Horticulture}

- Problem/Need. RO-treated seawater has the potential to damage plants used for landscaping outside and inside the home and in parks, open spaces, etc. This is also an issue with certain reclaimed waters and brackish groundwaters. In the case of seawater, 
there are three principal constituents of interest: sodium, chloride, and boron. Acceptable levels of these three constituents for common plants, soil types, and climates need to be established.

- Objective. Establish acceptable levels for boron, chloride, and sodium for plants common to households, yards, and open space in the United States as well as selected soil types and climates where seawater desalination is a viable candidate water source. The results from this research would allow utilities to use alternative water supplies with a quantitative understanding of potential landscaping impacts.

- Approach. Conduct a survey of existing literature to identify relevant plants, soil types, and climates. Document long-term plant responses in areas where these constituents occur at elevated levels. Conduct a field test to refine information identified in the earlier studies. 
This Page Intentionally Left Blank 


\subsection{NATIONAL RESEARCH AREA: ALTERNATIVE TECHNOLOGIES}

Alternative technologies are broadly defined as those that are not solely based on RO or other membrane-based processes. Alternative technologies hold the promise of leapfrogging the performance of current-generation, dominant technologies. With the high reward promised by these technologies, however, comes high risk.

The Alternative Technologies State-of-the-Science report identified a range of research priorities:

- Nanostructured, high flux membranes: Biomimetic; electrostatic; ion exchange

- Membrane surface modification for fouling, scaling control

- Hybrid systems for synergistic performance; RO/ED

- Draw agents, membranes, unit operations for forward osmosis

- New hydrate formers, separation processes for clathrate processes

- Low-temperature thermal desalination

- Capacitive deionization (CDI)

- Robust, inexpensive point-of-use (POU) and small capacity systems

Participants at the Water Innovation Symposium considered this list in combination with the research areas generated during the Source Waters/User Needs Meeting to frame four research agendas and associated research projects.

\subsection{Research Agenda: Biological Treatment}

\section{Research Project: Feasibility of Biological Desalination}

- Problem/Need. Advances in biotechnology might increase drinking water production.

- Objective. Examine the potential for contributions from biotechnology and the biologic sciences contributing to the production of potable water at useful scales.

- Approach. Support research in four areas: (1) Use of halophytes in trickle flow systems or membrane bioreactors to sequester salts; (2) Capture of transpiration
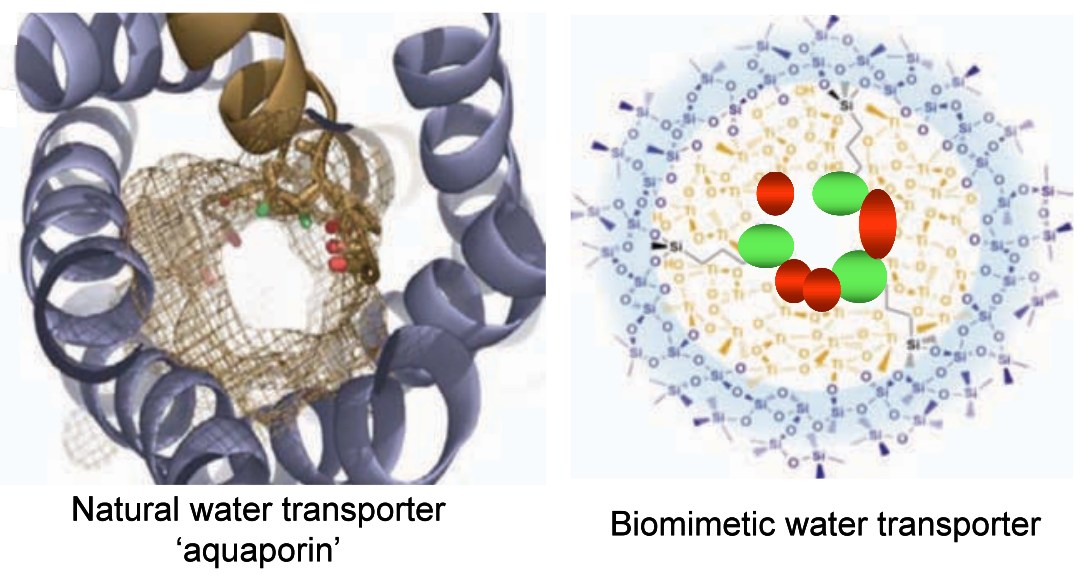

Biomimetic water transporter

A theorized biomimetic membrane (right) based on natural structure. Plants and animals use a variety of methods and structures to filter salts from fluids. Such natural physical structures can serve as models for biomimetic membranes with increased selectivity. (Courtesy of K. Leung, J. Brinker, and S. Rempe, Sandia National Laboratories.) 
vapor from halotolerant higher plants; (3) Light-driven flocculation of salt using constructed micelles; and (4) Construction of designed membranes with biomimetic pores. Evaluate issues of growth, system stability, disposal of wastes, and other factors.

\section{Research Project: Integrated Biological Processes for Salinity Control}

- Problem/Need. Biological processes may provide salinity control strategies.

- Objective. Consider biological processes individually, or as steps, in concentrate minimization efforts.

- Approach. Proposed projects should have high potential for technological advancement and high potential for successful application, while using less energy than traditional desalting processes. Desirable criteria are that the biological process should be robust, scalable, and low cost. An example of biological process is biological sulfate reduction, whereby an anaerobic reactor reduces sulfate to sulfide, with the reoxidation and removal of elemental sulfur.

\subsection{Research Agenda: Hybrid Systems}

Some impaired feedwaters and seawaters are difficult to cost-effectively treat with conventional technologies and processes. Hybrid systems, however, might result in lower energy consumption, high recovery potential, mineral extraction, and concentrate minimization.

\section{Research Project: RO/ED in Series and/or in Parallel}

- Problem/Need. By combining RO and ED systems in series and/or in parallel, each technology and the system as a whole can be optimized, resulting in higher recovery and potentially leading to mineral recovery with zero (or near-zero) liquid discharge.

- Objective. Develop hybrid systems that can treat very difficult brackish source waters.

- Approach. Series-Model combined system(s) to fully demonstrate optimization of recovery, energy, cost, and to determine source water salinity limits for treatability. Examine ED stack design and optimization for lower costs and suitability for treatment
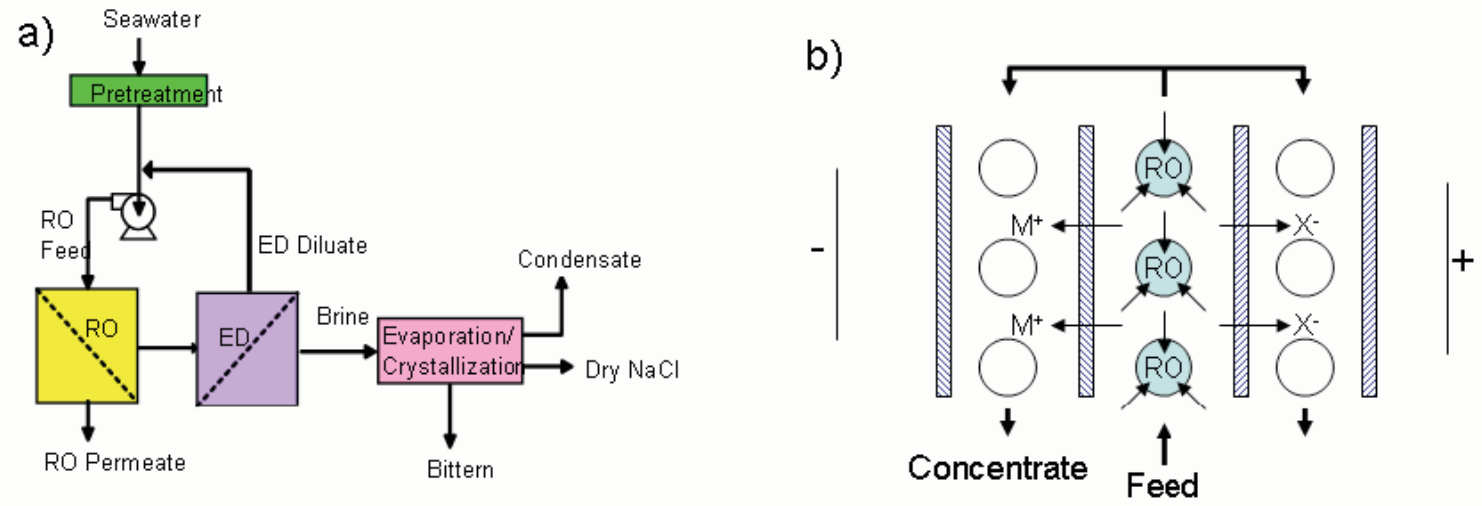

Hybrid Desalination Systems. a) Series hybrid RO/ED schematic, recycling RO concentrate, with salt recovery. b) Proposed parallel hybrid RO/ED incorporating hollow fiber RO membranes into an ED cell. (From T.A. Davis (a) and Pellegrino, Gorman, and Richards (b) as contained in Miller, James E., and Thomas M. Mayer, State-of-the-Science Report Number 2, A Critical Review of Alternative Desalination Technologies. Paper presented at the Technology Innovations Workshop.) 
of RO concentrates. Develop flow schemes to eliminate any need for salt additions to dialysis streams. Conduct pilot work with existing technologies to validate modeling results. Parallel—Design parallel RO/ED systems. Create flow schemes. Research ROcapillaries for inclusion in a parallel RO/ED system. Conduct benchtop-scale proof of concept testing.

\section{Research Project: Integrated Treatment of Brackish Water Concentrate and Seawater}

- Problem/Need. Disposal of concentrate from brackish water desalination is a potentially difficult problem that might be solved if the concentrate were used as a feedstock blend for seawater desalination plants.

- Objective. Solve the problem of inland brackish water RO concentrate disposal through beneficial use by lowering seawater RO energy use.

- Approach. Quantify potential benefits and applicability. Identify institutional constraints. Define integrated system configuration(s). Quantify benefits (economic and environmental). Pilot test to optimize and demonstrate the approach.

\subsection{Research Agenda: Alternative Membranes}

Large-scale desalination processes have been pursued for more than a half century. Through continual improvements, conventional technologies today are remarkably efficient and reliable. Operational limits (e.g., recovery and fouling) might still be improved to reduce cost. Alternative membrane-based desalination processes offer the promise of lower energy consumption, lower fouling, and higher freshwater production.

\section{Research Project: Membrane Distillation}

- Problem/Need. Membrane distillation uses low heat source (waste heat) to drive vapor through a membrane followed by condensation on the other side. Recent research has focused on polymeric and inorganic membranes. Further research is needed to establish the viability of manufacturing such membranes on a large scale, developing scalable processes, and establishing the process economics.

- Objective. Demonstrate the viability of producing low cost drinking water through the use of low grade, inexpensive heat sources to drive a desalination process. Achieve plants with smaller footprints.

- Approach. Determine scalability of proposed membranes. Demonstrate process viability and economics on a pilot scale using laboratory and field testing. 


\section{Research Project: Forward Osmosis}

- Problem/Need. Forward osmosis (FO) has the potential to avoid some of the limitations of current desalination and water reuse technologies. However, a robust membrane for FO needs to be developed, and there is a need for a draw solute that can be economically separated from the freshwater and recycled.

- Objective. Develop a FO desalination process that can operate at a cost at least $20 \%$ lower than RO (i.e., $6 \mathrm{~kJ} / \mathrm{kg}$ of freshwater produced) and at a higher recovery than RO.

- Approach. Develop a FO membrane with minimal internal concentration polarization and high salt and draw solute rejection. Develop draw solute(s) with high osmotic driving force and low toxicity, and an economical separation process for the freshwater from the draw solute.

\section{Research Project: Nanostructured High Flux Membranes}

- Problem/Need. Conventional membrane separation processes are energy intensive and incur performance penalties. These can potentially be overcome through chemical or electrostatic control of ion and water transport in nm-scale structures.

- Objective. Achieve order of magnitude increase in performance of RO and ED systems, and significant reduction in energy use and costs of desalination. This research should demonstrate that nanostructured membranes can produce order- of -magnitude improvements in conventional RO or ion exchange membranes at the laboratory scale.

- Approach. Investigate biomimetic membrane filtration in synthetic systems. Research selfassembly techniques in polymer, ceramic, nanotube compacting, or other nanostructure fabrication.

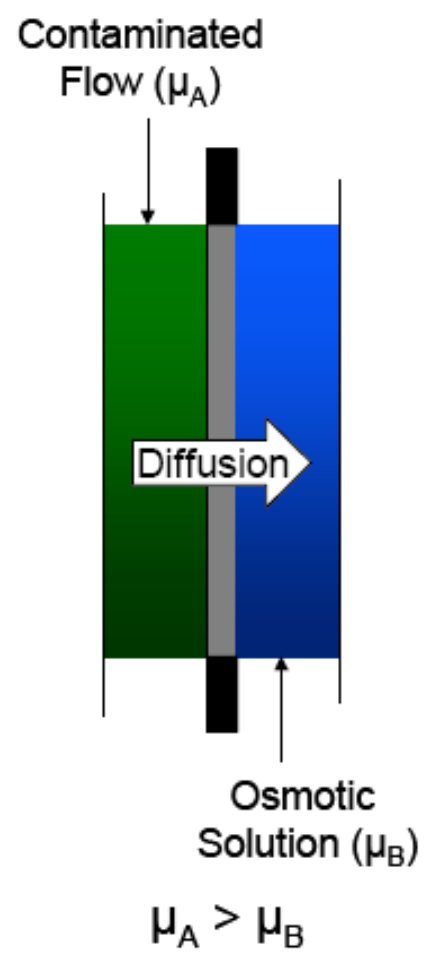

Forward Osmosis.

Flow of water across a semipermeable membrane from solution with high chemical potential (low salt concentration) to low chemical potential (high salt concentration). (Miller, James E. and Thomas M. Mayer, State-of-the-Science Report Number 2, A Critical Review of Alternative Desalination Technologies. Paper presented at the Technology Innovations Workshop.)

Research Project: State-of-the-Science Review of Nanostructured Membranes

- Problem/Need. To dramatically improve membrane performance, new materials and technologies (possibly from non-water technology fields) must be examined.

- Objective. Improve membrane productivity, rejection, selectivity, and manufacturing reproducibility (consistency of product).

- Approach. Identify all relevant ongoing research in nanostructured materials and technologies in all applicable fields. Identify synergies with water 
production/desalination processes. Establish research priorities leading to development of water-specific technical products. Identify opportunities for co-development (cofunding) with, for example, gas separations or biomedical processes.

\subsection{Research Agenda: Offrhore Desalination}

Siting desalination plants in coastal areas is often an expensive challenge; land costs are high and the Not In My Back Yard mindset can work to slow permitting and construction.

Siting desalination plants offshore may mitigate the environmental impacts of current facilities and reduce project costs and implementation schedules. Additionally, offshore siting offers the opportunity to better utilize primary energy sources.

Research Project: Offshore Intakes for Offshore Desalination

- Problem/Need. Siting desalination plants in or near coastal urban areas (where the demand for projects is highest) is limited by concentrate disposal concerns, urban planning constraints, and land costs. Offshore desalination plants might prove to be cost-effective and more easily permitted.

- Objective. Reduce project costs and shorten construction/startup schedules, thus realizing water cost reductions.

- Approach. Phase 1-Develop concept feasibility by demonstrating the potential for energy reduction, process productivity improvements or environmental mitigation potential offshore intakes, and use of primary energy supplies. Phase 2-Establish demonstration projects to test the successfully proven concepts. The second phase should also address the institutional issues associated with implementing the concept. 
This Page Intentionally Left Blank 


\subsection{NATIONAL RESEARCH AREA: CONCENTRATE MANAGEMENT TECHNOLOGIES}

Concentrate management is a critical concern in inland areas where ocean discharge is impractical. New concentrate management approaches are needed that that will:

Reduce volumes. The less voluminous the concentrate stream, the less concentrate that must be disposed and the greater percentage of water that can then be beneficially reused.

Reduce energy and other costs. Provide for beneficial use. Concentrate streams may contain elements that can be beneficially used in industrial and/or agricultural processes. Research should be focused on identifying beneficial use elements and creating cost-effective methods for separating them from the concentrate stream.

Overcome/address institutional

barriers. Institutional barriers drive up the cost of concentrate management. Research should focus on supporting science-based

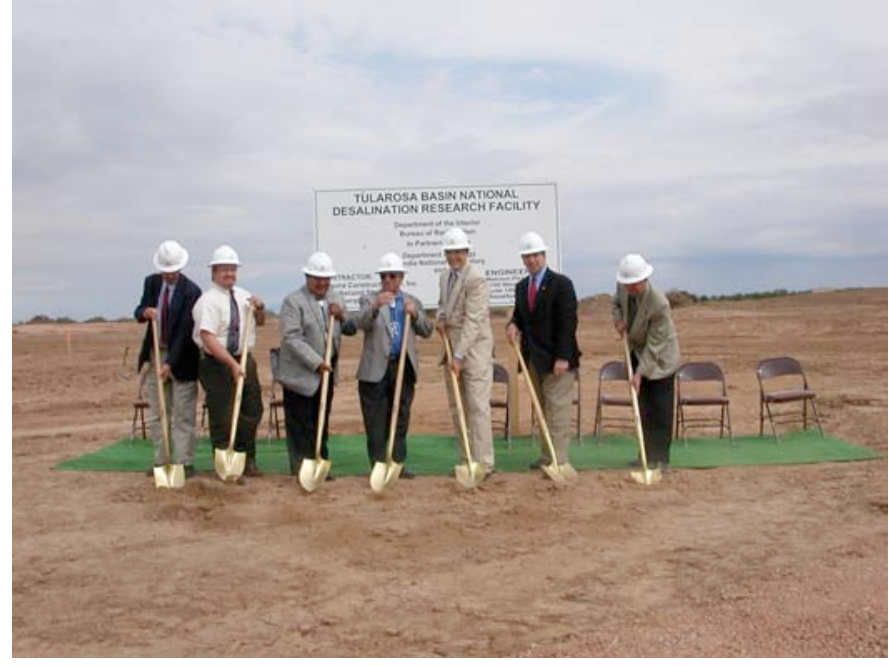

Ground breaking for the Tularosa Basin National Desalination Research Facility in Alamogordo, New Mexico. regulation that is flexible.

The Concentrate Management State-of-the-Science report identified a range of research priorities for consideration:

- Do state-by-state mapping of disposal options

- Expand concentrate management guidelines

- Map concentrate chemistry to soil remediation targets

- Develop regional concentrate management guidance

- Improve understanding of material/high salinity brine interactions

- Consider impacts of co-siting of inland desalination with wastewater treatment power facilities

- Create markets for salts

- Minimize/avoid contamination of concentrate from seawater RO plants

- Improve understanding of antiscalant fate in concentrate management

Participants at the Water Innovation Symposium considered this list in combination with the research areas generated during the Source Waters/User Needs Meeting to frame five research agendas and associated research projects. 


\subsection{Research Agenda: Disposal, Fundamental Research}

Additives that are routinely used to control scaling and biofouling in desalination facilities can accumulate in the concentrate. Biological growth can also alter the composition of the concentrate. Each can limit concentrate disposal options.

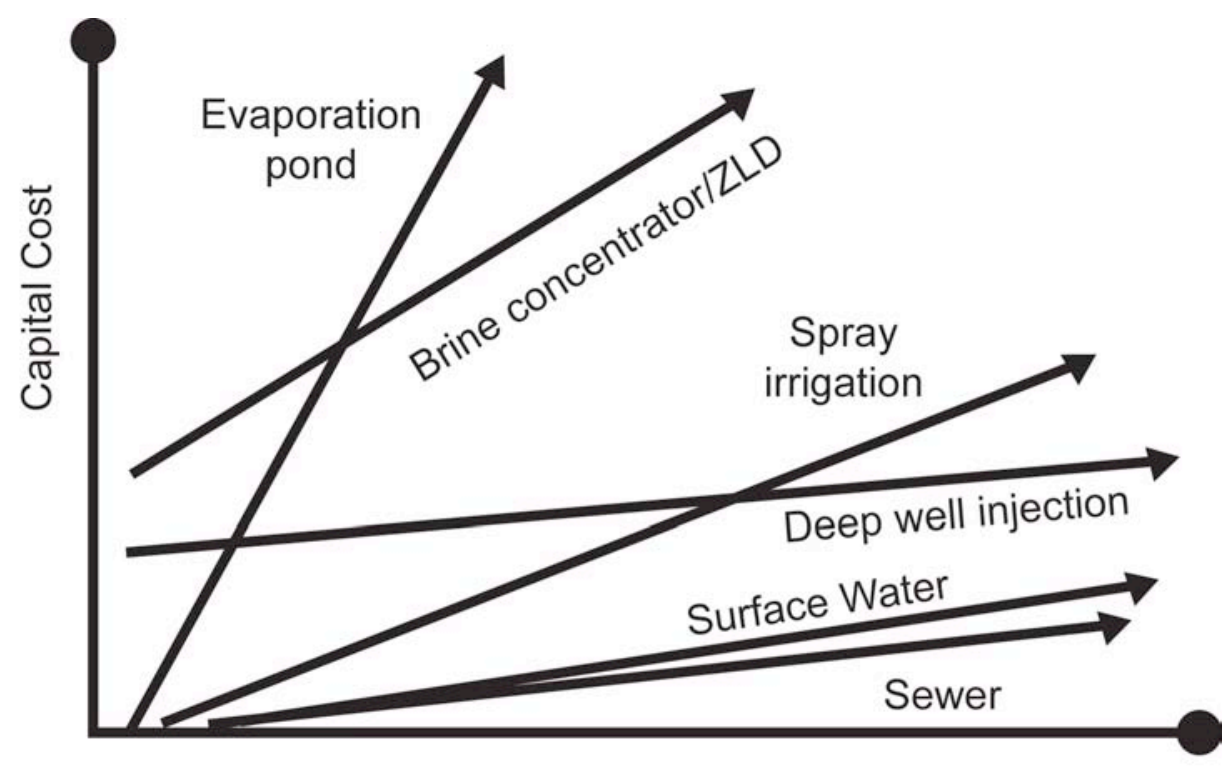

\section{Concentrate Volume}

Scale-dependent capital costs of concentrate disposal options. (after Mickey, Mike, P.E., Ph.D. State-of-the-Science Report Number 3, Concentrate Management. Paper presented at the Technology Innovations Workshop.)

The potential for desalination concentrate to adversely impact aquatic life and the environment (both marine and freshwater) is a major impediment to successful permitting of concentrate discharge.

\section{Research Project: Improved Understanding of Additive Fate and Transport}

- Problem/Need. Additives used in desalination facilities can limit concentrate management options. For instance, use of chlorine to control biological fouling can create disinfection by-products in the resulting concentrate. The presence of antiscalants in concentrate may limit discharge or beneficial use alternatives and may create public concern.

- Objective. Enable water suppliers to address real or perceived issues related to the presence of additives in concentrate through a better understanding of additive fate and transport.

- Approach. Compile existing information on additives typical of desalination facility operations, including naturally derived additives, and identify knowledge gaps in our current understanding of additive fate, transport, and risk (human health and environmental). 
Research Project: Impacts of Desalination Concentrates on Aquatic Life and the Environment

- Problem/Need. Current methods used to assess impacts of concentrates on aquatic life and the environment are significantly lacking; they do not adequately address the potential for bioaccumulation or the impacts of emerging contaminants (e.g., selenium, arsenic, radionuclides, xenobiotics). Additionally, the current methods for toxicity screening for wastewater plants are also overly stringent and in need of refinement.

- Objective. Better understanding of concentrate impacts on the environment will lead to more informed concentrate management decisions.

- Approach. Critically evaluate existing methods for assessing impacts of concentrates on aquatic life and the environment. Identify weaknesses and develop needed improvements.

\section{Research Project: Hybrid Techniques for Zero-Liquid Discharge}

- Problem/Need. Zero-liquid discharge facilities are popular but expensive.

- Objective. Consider potential cost-reducing hybrid techniques for zero-liquid discharge including electromagnetic fields to suppress salt crystal formation, accelerated precipitation using modified lime clarification and secondary RO treatment, biological sulfate reduction to remove sulfate-based scalants, blending RO and ED/EDR technologies to achieve synergy, biomimetic crystallization, and electrostatic ion pumping.

- Approach. Conduct a literature review on available and potential technologies, followed by integrated bench-scale proof-of-concept testing of two or three processes to achieve greater than $95 \%$ total system water recovery. A critical review of process robustness and economic feasibility of promising processes will precede pilot testing.

\section{Primarv Desalination}

Reverse Osmosis/Electrodialysis/Thermal

$\underline{\text { SGSP }}$

$\underline{\text { MEMS }}$

BCRS

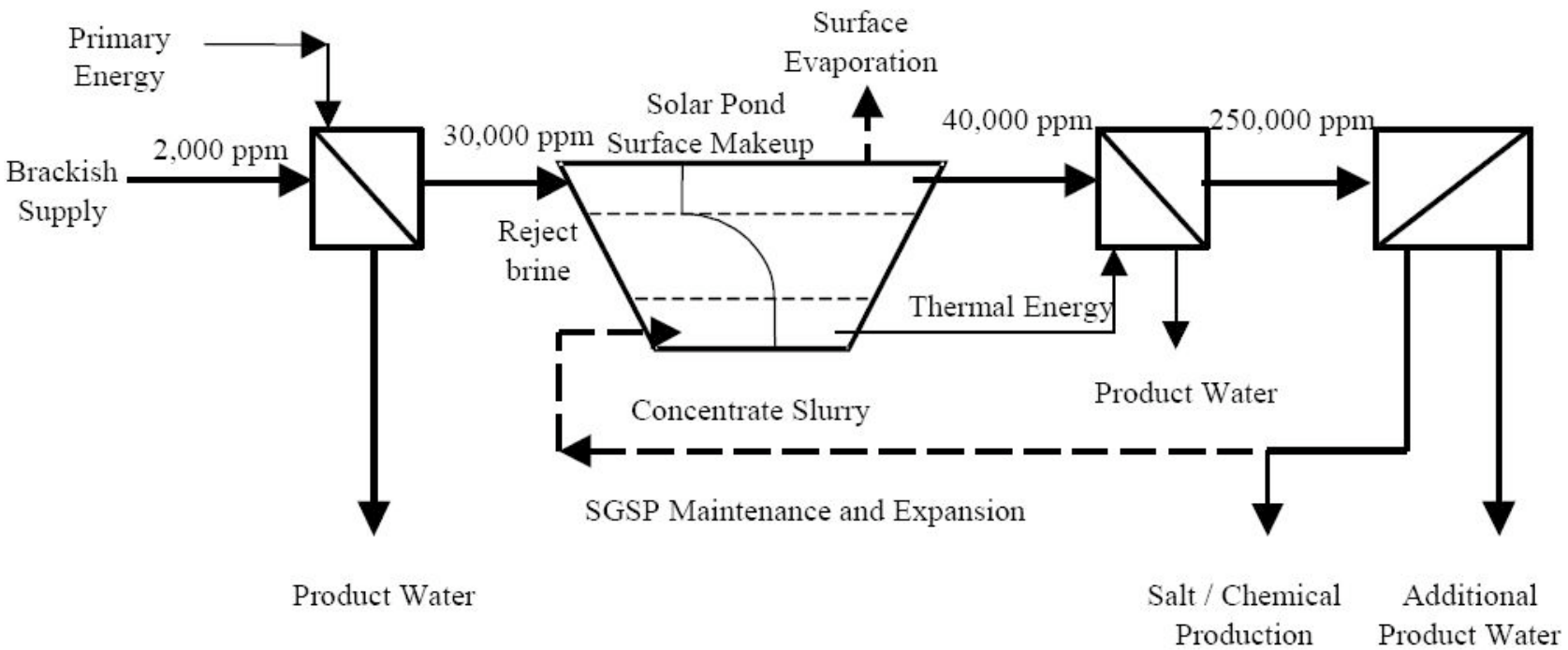

Schematic of a hybrid, multi-approach zero-discharge desalination system. Cost-effective Zero Liquid Discharge (ZLD) techniques will enable the desalination of vast brackish water resources, many of which underlie water-scarce regions of the West and Southwest. (http://www.usbr.gov/pmts/water/media/pdfs/report089.pdf) 


\subsection{Research Agenda: Disposal, Applied Research}

There are five "conventional" concentrate disposal methods for inland areas: surface water disposal, discharge to existing wastewater collection systems, downhole injection of concentrates, land application, and evaporation ponds.

There are unknowns and weaknesses associated with these conventional methods: The longterm impacts and effects of brine discharge on treatment plant operations are unknown; lining evaporation ponds to keep them from leaking is expensive; and the fundamentals of land application are not completely understood.

Research Project: Self-Sealing Evaporation Ponds

- Problem/Need. The cost of lining evaporation ponds sharply limits their use, highlighting the need for cheaper, more robust alternatives.

- Objective. Provide a substantially cheaper and more leak-resistant evaporation pond by developing geomaterial liners (possibly with

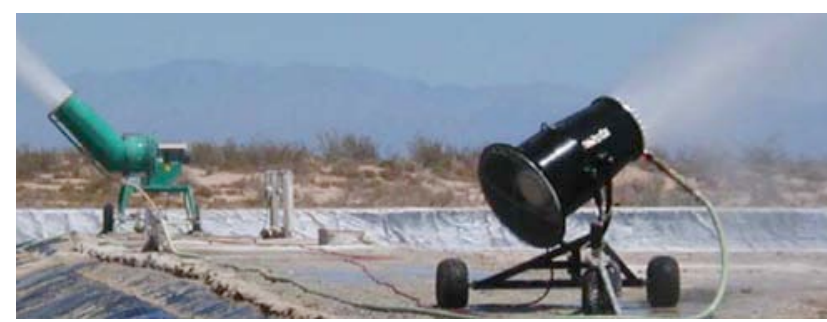

Evaporation enhancement to reduce the footprint of inland desalination facilities.

(http://www.epwu.org/desal_presentations/session02/e rik_jorgensen.pdf) additives) that incorporate concentrate components to self-seal (heal) liners.

- Approach. Identify self-sealing liner materials by conducting bench-scale permeability testing of candidate material growth/expansion capacities, followed by pilot testing of the best materials at an inland desalination site (e.g., El Paso, Texas, and/or Tularosa, New Mexico).

\section{Research Project: "Low-Tech" Methods for Enhancing Evaporation}

- Problem/Need. Evaporation processes are land-intensive. Novel evaporation enhancement processes might decrease the process footprint.

- Objective. Reduce land requirements for concentrate management by providing an additional treatment tool to maximize evaporation rates in evaporation ponds (either for final dry disposal or for reducing the brine volume for ultimate disposal in a brine line).

- Approach. Identify viable enhanced evaporation methods and demonstrate their largescale implementation through a two step process: (1) Identify and screen new enhanced evaporation methods through an international literature review and identify and rank documented technically feasible alternatives for application in the United States; and (2) Conduct pilot- and demonstration-scale testing at an existing evaporation pond or equivalent site.

\section{Research Project: Impact of Concentrates on Wastewater Treatment Plants}

- Problem/Need. Increasing discharge of concentrate to wastewater treatment plants (WWTPs) may impair the performance of the latter. Failure of any unit operation may impact effluent quality and permit requirements. 
- Objective. Develop a better understanding of the impact of concentrates on WWTP unit operations, particularly as the volume of these concentrates increases. Understanding the impacts on treatment, operations and maintenance, effluent quality, and sludge disposal will help water utilities evaluate WWTP disposal as a potential concentrate disposal option.

- Approach. At the bench or pilot scale, establish the potential impacts of concentrate inputs to biological processes, corrosion of equipment, effluent discharge standards (nutrients, naturally occurring radioactive materials, etc.), sludge handling and residual disposal, and potential reuse of effluent. Both chronic and acute toxicity of the concentrate on the microorganisms in the plant should be assessed. Task One: Test brines in increasing concentrations against both aerobic and sludge respiration. Task Two: Vary the brine components in order to determine the sensitivity of the microbes to the individual components of the brine. Task Three: Test the influence of effluent quality on the functioning of wastewater treatment plants at the bench-scale.

\subsection{Research Agenda: Beneficial Use, Fundamental Research}

\section{Research Project: Selective Contaminant Removal to Produce Saleable Product(s)}

- Problem/Need. Removing contaminants of concern and selectively extracting valuable constituents to produce a by-product from desalination concentrate are both critical needs.

- Objective. Create revenue from the sale of concentrate by-products to offset operating costs.

- Approach. (1) Characterize the range of materials in concentrate based on the type of source water, e.g., seawater, brackish groundwater, wastewater effluent; (2) Identify available technology for selective ion removal; (3) Develop a list of potentially saleable products; and (4) Develop new methods to operate desalination plants so as to minimize the addition of contaminants from pretreatment or other processes.

\section{Research Project: Nano-Coagulation of Silica}

- Problem/Need. Silica removal is a critical challenge to inland desalination as it limits water recovery and concentrate disposal options.

- Objective. Dramatically increase recoveries and lower costs of silica removal.

- Approach. Develop novel nano-materials (metal oxides and metals sorbed on nanooxides) that can rapidly and effectively remove silica from solution by establishing the ability of designer nano-materials to abstract silica from solution. Optimize (e.g., feed rate, sequencing) and pilot test at an inland desalination site.

\section{Research Project: Minimization of Antiscalants and Biocides}

- Problem/Need. Environmental and regulatory agencies frequently object to disposal of antiscalant and biocidal chemicals present in concentrate (marine, brackish, wastewater). In addition, these chemicals complicate beneficial product recovery and increase operating costs. While electromagnetic antiscalant devices and systems are available, the manufacturer's claims are not independently validated.

- Objective. Develop understanding and system design for minimizing use of antiscalants and biocides and their impact on concentrate. Develop more options for disposal or beneficial product recovery to simplify or reduce permitting costs and timescales. 
- Approach. (1) Identify alternative chemicals and test effectiveness at bench scale; (2) Identify and test non-chemical options (e.g., electromagnetic conditioning); (3) Identify and test biological pretreatment options; and (4) Optimize total process design.

\section{Research Project: Selective Precipitation of Concentrate Salts}

- Problem/Need. The potential for beneficial reuse of common RO salts is currently limited by our inability to separate and purify individual salt compounds, and to match these salts with specific market uses. Selective salt precipitation and recovery from RO concentrate has been developed and patented outside of the United States, but there has been minimal domestic effort. Recovery and reuse of concentrate salts would substantially reduce environmental impacts relative to conventional concentrate disposal methods (e.g., surface water discharge, evaporation ponds). The reduction in cost of concentrate disposal would vary depending on site-specific salts and their markets.

- Objective. Develop selective precipitation and purification methods for common RO concentrate salts and identify potential regional markets for beneficial reuse.

- Approach. (1) Develop selective precipitation and purification methods by identifying common RO concentrate salts, developing precipitation processes and identifying chemical reaction parameters, and evaluating purification techniques; and (2) Identify potential regional salt reuse markets by surveying and documenting current salt sources, uses, costs, and market factors that impact costs and analyzing the potential for RO concentrate salts to become integrated in the current salt markets, and recommend strategies for this integration.

\subsection{Research Agenda: Beneficial Use, Applied Research}

\section{Research Project: Recreational and Environmental Use of Concentrates}

- Problem/Need. Beneficial reuse of concentrate in recreational/environmental settings might enhance public appreciation while providing a concentrate disposal path.

- Objective. Create new concentrate disposal options and improve public perception by applying concentrates in health spa or environment/recreation improvements.

- Approach. (1) Identify roadblocks and learn from historical projects through literature reviews, workshops, on-site studies, and develop a plan to overcome past problems with new solutions and options; (2) Develop a methodology for including site hydrology, ecological needs and concentrate flow and chemistry and develop tools to identify appropriate locations; and (3) Develop a pilot project to test some of the new concepts and verify absence of unexpected environmental issues.

\section{Research Project: Nontraditional Agricultural Methods for Sustainable Concentrate Management}

- Problem/Need. Innovative agricultural applications can potentially add to the portfolio of available concentrate management options for inland desalination facilities. These applications include: Sequestration of salts by plants; use of concentrate as wash water by concentrated animal feeding operations; and use and development of halophilic plant species. Challenges include accumulation of toxic elements (e.g., selenium), salt accumulation in soils, and potential groundwater impacts, all of which can limit the sustainability of the process. In addition to these technical challenges, communication barriers exist between agricultural and water supply stakeholders. 
- Objective. Identify, develop, and demonstrate new agricultural-based methods to promote cost-effective and sustainable concentrate management.

- Approach. Assess current state-of-the-science in nontraditional agricultural methods for concentrate management.

Research Project: Brine Stream Water Quality Effects on Agriculture and Horticulture

- Problem/Need. Plants are sensitive to certain salts found in concentrate (chloride, boron, sodium, hardness, $\mathrm{pH}$, sodium adsorption ratio). Understanding the actual impact is a first step to using brine in commercial horticulture and agriculture, for the rejuvenation of wetlands, and by the utility internally.

- Objective. Minimize expensive methods of disposal by identifying a beneficial use of concentrate. Create a document that a utility could use to help market their brine.

- Approach. Phase 1-A critical review to summarize impacts of water quality on commercial agriculture and horticulture. This review must include an assessment of the impact of a typical brine stream, and not just its components, on plant life and health. Phase 2-Establish the impact of a typical brine on plants and develop guidelines on water quality for various types of plants given soil and climate type.

\subsection{Research Agenda: Energy Consumption and Recovery}

\section{Research Project: Demonstration of Energy Recovery in Concentrate Management}

- Problem/Need. Improving energy recovery reduces the overall cost of desalination, thus increasing economic feasibility.

- Objective. Enable the development of additional sources of water by encouraging innovation in energy conservation in concentrate management processes.

- Approach. Demonstrate energy-saving technology candidates for concentration of membrane concentrate streams at the bench scale to identify best candidates. Demonstrate the practicality of the best candidate energy-saving technologies at full scale.

Research Project: Co-Siting of Desalination Facilities with Wastewater Treatment Facilities, Power Generation, Oil and Gas, and Other Industrial Facilities

- Problem/Need. The concentrate-specific benefits of co-siting desalination facilities with other municipal and industrial operations must be determined.

- Objective. Provide a cost-effective concentrate disposal solution by using low-cost power and/or providing industrial feed water.

- Approach. Convene workshop with industry representatives to discuss and evaluate potential benefits and issues from co-siting of facilities. Identify and develop model approaches. Identify and follow up on case studies. Develop a decision tool that identifies potential opportunities for co-siting. 
This Page Intentionally Left Blank 


\subsection{NATIONAL RESEARCH AREA: INSTITUTIONAL ISSUES}

The Institutional Issues in Desalination and Water Purification Technologies report prepared for the Institutional Issues Workshop defined institutional issues generically as non-technical barriers to the implementation of desalination. The set of issues explored in the report consisted primarily of the following:

- Environmental concerns. Many environmentalists and other stakeholders are concerned about impingement and entrainment (I\&E) at intakes and the impacts of concentrate discharges on aquatic organisms. There is also a concern that the relatively high energy usage of desalination and other membrane process applications will result in high emissions of greenhouse gases.

- Permitting issues. In some states (e.g., California), several state or federal permits are needed to build a desalination facility.

- Growth issues. Occasionally environmentalists, natural resource agencies, or politicians may oppose a desalination facility simply to limit growth.

- Siting issues. Some citizens oppose co-locating desalination plants with existing power plants because the first will prolong the life of the second.

The Institutional Issues in Desalination and Water Purification Technologies report identified a range of research priorities for consideration by participants at the Institutional Issues Workshop:

- Regulatory Framework and Protocol Needs

○ Develop a workshop (or series of workshops) that brings regulators from different states and agencies together, along with various technical experts, to review desalination concerns and permitting procedures.

- Establish an open, advance dialogue with regulators to explain desalination issues and needs, and seek to build a reasonable set of protocols for permit approval.

○ Conduct research that generates key findings, or establishes desalination-suitable testing/monitoring protocols.

- Define some standardized approaches to desalination permitting and other regulatory issues.

- Citizen and Public Official Outreach Needs

- Explore ways of communicating about the problem(s) to be solved by adding desalination to the portfolio of local supply options.

- Research how to develop and portray a "no desalination" baseline future that may help communities focus on their alternatives.

- Investigate what growth scenarios are likely under alternative future water supply options (this could well be done in conjunction with the "baseline" study noted above).

- Better articulate the benefits of desalination.

$\circ$ Measure and communicate the potential environmental benefits of desalination. 
- Energy-Related Research Needs

- Explore ways that the water sector can become a cutting-edge adopter of alternative energy and/or energy-saving technologies.

- Feedwater Research Needs

- Determine if the actual rates of I\&E at stand-alone estuary and ocean facilities are likely to occur at a magnitude of concern.

- Define what types and scales of coastal restoration efforts might be feasible to offset environmental impacts.

- Consider whether the cumulative impacts of multiple facilities in the coastal zone result in environmental harm.

- Evaluate if desalination impacts would be greater or lesser if there were few large facilities along the coast, or many smaller ones.

- Assemble data on the quality of feedwater taken from power plant discharges and the degree to which different pretreatment options mitigate any concerns.

- Concentrate Disposal Research Needs

- Determine actual coastal dilution ratios/consider dilution via the radial jet mixing of power plant flows in the models that are currently used.

- Determine the water quality of the coastal discharge that results from blending with power plants.

\subsection{Research Agenda: Energy Cost Reduction}

Energy costs are a significant concern at desalination facilities; as energy costs rise, desalination become less attractive. Thus, minimizing energy consumption and/or utilizing alternative energy technologies has become increasingly important.

\section{Research Project: Alternative Energy and Desalination}

- Problem/Need. Rising energy costs are driving up the cost of desalinated water; levying a greenhouse gas emission tax in the future would further increase costs. Increasing reliance on alternative energy would provide a hedge against rising energy costs.

- Objective. Evaluate alternative energy use in desalination. Identify differential energy needs of desalination relative to existing water supplies.

- Approach. Determine the energy needed to deliver various types of water supplies for major national water systems from the source to the consumer including distribution, treatment, and disposal. Identify commercial or near-commercial energy technologies from other sectors that could be applied to desalination. Screen and evaluate alternative energy technologies that could be applied to enhance efficiencies in desalination in the future. Promote public awareness of the interrelationship between water supply and energy use.

\subsection{Research Agenda: Environmental Considerations}

The potential impacts of desalination facilities on the surrounding environment can be a significant hurdle to installation and operation. There is a need to develop cost-effective impact analysis methods and to better understand emerging sources of potential impact. 
Research Project: Impacts on Coastal Habitats and Biota

- Problem/Need. A number of concerns have been raised by regulatory agencies, policy makers, and environmental organizations about the potential environmental impacts of seawater desalination. Yet actual effects are largely unknown. It is also unclear to what extent results from the handful of environmental impact assessments (EIAs) conducted for individual desalination facilities can be extended to other sites. To reduce uncertainty about the potential environmental consequences of seawater desalination, data from current desalination EIAs and related studies from other types of projects (e.g., 316(b) studies) should be used to conduct a comprehensive analysis of intake and discharge impacts.

- Objective. Use existing data from desalination EIAs, cooling water intake studies, and brine discharge monitoring associated with National Pollutant Discharge Elimination System (NPDES) permitting to analyze the environmental impacts of seawater desalination, identify data gaps, and develop monitoring protocols (including factors to consider in defining a baseline).

- Approach. Identify existing impingement and entrainment data (e.g., from 316(b) studies and 316(b) regulatory development docket) and determine what data may be applicable to seawater intakes. Identify existing brine discharge monitoring data and determine applicability to the evaluation of desalination. Identify any applicable environmental data from existing seawater desalination EIAs. Assemble and prepare database of available data useful for evaluating the potential and relative magnitude of environmental impacts of seawater desalination intakes and discharges.

\section{Research Project: Survey and Summary of Case Studies re. Coastal Alternate Intake} Methods

- Problem/Need. Different intake methods have different environmental and cost impacts. The industry needs objective information that can be used to examine options and impacts.

- Objective. Provide information that can be used to adequately examine intake options and impacts.

- Approach. Survey existing projects (both national and international) summarizing the methods they use for intakes as well as costs, potential environmental impacts, etc. The result will be a compilation of existing technologies (beach wells, open intakes of various kinds, etc.), lessons learned, where they are applicable, where they are not, and suggestions for research. Research to be followed by development of design "go-bys" and research into alternative intake design.

\subsection{Research Agenda: Alternative Water Supplies and the Role of DESALINATION}

Desalination is but one means for meeting current and future water demand; there is a need to better understand and communicate the role of desalination vis-à-vis alternative water supplies in water supply planning. 
Research Project: Tools and Standards to Determine/Assess Methods and Capacity of Alternative Water Supply Methods

- Problem/Need. One barrier to some desalination projects is negative environmental impacts. Desalination may become less favored if alternative supply methods are improved, maximized, and publicized. While there may be existing programs and requirements for governments and suppliers that demonstrate traditional methods of conservation, water reclamation, etc., it can be argued that the cheaper and environmentally beneficial alternatives are not fully utilized before desalination is considered. Local governments can reduce the cost of Clean Water Act compliance through alternatives such as wastewater reclamation, stormwater retention, urban runoff reuse, treatment wetlands, etc.

- Objective. Develop tools and standards to determine and assess the capacity of alternative water supply methods.

- Approach. (1) Compare and validate assessment methods used to ensure that alternative methods are being maximized; (2) Distinguish the potential and approach of alternative water supply methods for inland (brackish) and coastal (seawater) regions; (3) Prioritize areas for investment in new technology for alternative methods; (4) Publicize the extent to which alternative methods have been assessed and maximized; (5) Compile lessons learned from case studies and best practice models for efficiency and scientific methodology; (6) Consider the Clean Water Act benefits that the alternative methods provide; (7) Assess the role of alternative supply methods during drought events.

Research Project: Approaches to Identify and Promote Alternative Water Supplies through Case Studies

- Problem/Need. The water supply industry has repeatedly performed evaluations of water supply alternatives when considering capital investments to assure the future reliability of water supplies. However, the results of each individual water agency's future water supply evaluation are rarely assembled for non-water agency stakeholders so the latter can be assured that alternatives such as desalination are appropriately evaluated, justified, and prioritized.

- Objective. Provide case study examples of alternative water supply evaluations that have been completed and used by decision makers to prioritize and justify investments in new water supplies for their constituents.

- Approach. Develop five to ten case study examples of alternative water supply evaluations. The case studies should include various base water supplies and should delineate the motivations and rationale for different agency decisions to invest in various water supply alternatives such as conservation, recycling, and desalination.

Research Project: Portfolio Approach to Water Supply Planning to Reflect the Different Risks and Benefits of Desalination Relative to Alternative Water Supply Options

- Problem/Need. In the face of changing water supply and demand, yield reliability (in terms of drought resistance and infrastructure reliability) is one of the key motives for adding desalination (and reuse) to the local or regional portfolio of water supply options. Every water supply option carries some type and level of risks, costs, and social benefit. Comparing water supply options in a way that facilitates a more fully informed and transparent basis for utility/community investment decisions thus requires a more complete and systematic approach than traditional least-cost planning. A portfolio 
approach to evaluating water supply options would include risk premiums for reliability, and might also reflect other types of benefits that need to be considered when trying to provide a fair and comprehensive evaluation of desalination relative to other supply alternatives.

- Objective. Provide a basis for considering risk and benefit characteristics of desalination relative to other options, so that the water supply community can better understand the value (risk reduction premium) of adding desalination to a water supply portfolio, and can help communicate with stakeholders and public officials about the rationale for paying relatively higher costs in order to secure a more drought-resistant supply.

- Approach. Develop a conceptual and empirical basis for reflecting the value of droughtresistant yield reliability so that desalination (and reuse) can be compared on an applesto-apples basis with other water supply options.

\subsection{Research Agenda: Regulatory/Policy Considerations}

Currently, regulations, legislation, court decisions, and policies at the state and federal levels are significant hurdles to building and operating a desalination facility. There is a need to share information among regulators and policymakers so that new projects can benefit from the experiences of previous projects.

\section{Research Project: Summarizing Regional Case Studies to Summarize Policy} Modifications Regarding Water Rights

- Problem/Need. Inland and coastal communities share many common interests in discussions of water rights. Water rights issues are typically governed by historical agreements and newly

- developed regional solutions to water supply. These regional solutions involve agreements in which water allotments are increased for upstream users while coastal communities develop desalination-based supplies. Because both inland and coastal communities benefit from these regional agreements, both would share water rights and financial obligations for these projects. Sharing financial resources for the development of new desalination projects will enable a regional solution to water supply shortfalls and provide for prior agreement to provide water to all of the community, recreational, industrial, and environmental interests.

- Objective. Document and summarize regional water rights solutions.

- Approach. Phase 1-Document all known case studies of regional solutions of water supply improvements and include a summary of the way in which the complete portfolio of needs has been addressed. Phase 2-Perform multi-stakeholder review of these studies to validate these studies for application to other regions.

\section{Research Project: Regulatory Definition of Concentrate as a Hazardous Waste}

- Problem/Need. Concentrate from brackish groundwater desalination is currently characterized as a "hazardous waste." For state regulators, this triggers certain regulatory requirements that carry significant cost burdens which may in turn dissuade utilities from considering desalination. Examples of the burden include double-lining of evaporation ponds and overly stringent injection well standards.

- Objective. Obtain removal of concentrate from the "hazardous waste" category to allow for more uniform and cost-effective solutions across the United States. 
- Approach. Develop information necessary to achieve changes in regulatory requirements for use by Federal and State Governments. 
Research Project: Regulatory and Policy Review Case Studies

- Problem/Need. Permitting, regulatory, and legal issues can slow or stop implementation of desalination. Utilities and policy makers need case studies from successful

desalination implementation and from unsuccessful projects. This would allow barriers to be anticipated and potential policy changes to be implemented that would protect stakeholder concerns, while resulting in a less cumbersome approval process.

- Objective. Provide information to policy makers to allow streamlining of desalination implementation.

- Approach. Use U.S./international case studies to provide examples that highlight successful resolution of regulatory/policy issues surrounding desalination.

Research Project: Workshops to Discuss Desalination Project Permitting/Authorizing Approaches

- Problem/Need. The permitting/authorization of water sources (including water rights), public water system treatment, and residuals management are controlled by Federal and State statutes and regulations. Implementation policies add additional issues that must be addressed by water systems pursuing desalination. A sharing of information between regulators might grow the knowledge base on these issues.

- Objective. Enhance understanding of regulatory impediments to desalination through case studies and discussions of statutes and regulations.

- Approach. Convene workshops at which case studies can be presented and discussions of statutes and regulations fostered.

\subsection{Research Agenda: Outreach to Water Professionals}

Desalination professionals constitute a small fraction of water treatment professionals in the United States. To increase the visibility and understanding of desalination, the field must reach out to other water professionals. The training of professionals in desalination technologies must likewise be accelerated.

\section{Research Project: Call for Action for Education and Training of Desalination} Professionals

- Problem/Need. It is essential that desalination professionals have adequate training and education to provide the appropriate quality of water for its intended use, as well as to make certain that regulators are in tune with any unique aspects of desalination facility operation. Better understanding of the entire process and resulting product will result in more efficient regulatory approvals. Facilities will operate as intended from startup providing savings to owners and customers. Education and training will also assure that qualified staff are available to operate the facilities.

- Objective. Make all relevant constituents (academic, regulatory, industry, manufacturer) aware of the need for qualified professionals. Draw information from sources currently operating desalination facilities, such as the military and maritime cruise and shipping industries, to establish a curriculum for training as well as best practices.

- Approach. Collect data; develop relationships with education and training organizations to structure a recommended curriculum for different disciplines; work with regulators to develop modifications to certifications and operating parameters specific to desalting. 
Research Project: Water in 2030-A Call for Action to Develop a National Water Program for Promotion of Desalination and Training Future Water Professionals

- Problem/Need. Integrated water resource management will be critical in many regions of the country as water supplies tighten and demands increase. This issue transcends state and regional boundaries and so can be treated most effectively at the national level. In particular, there is a critical national role for coordination of training of future water professionals, for promotion of desalination as a component of integrated water management planning and for creation of a coherent framework in which state and local water policies can anticipate, address, and resolve future water crises.

- Objective. Greatly enhance the country's ability to meet its water industry needs, address trans-boundary water issues, and speed the adoption of desalination and water reuse technologies. A national water program might also hasten multi-scale water planning, elimination of regulatory redundancy (e.g., one-stop regulatory shopping), and recognition and resolution of environmental and societal concerns.

- Approach. Conduct studies to promote a national water program including:

- Projectthe manpower requirements and training required to address the Nation's future water needs; define a national program to promote creation of the appropriate professional training at universities or via other educational programs.

- Identify Federal programs that might be appropriate models for a national water program.

- Identify ways that Federal programs could promote increased use of desalination and water reuse to increase future water supplies, such as consolidation of permitting processes, promoting public/private partnerships, or incentive programs.

\subsection{Research Agenda: Improving the Understanding OF THE TECHNOLOGY}

\section{Research Project: Guidelines for Desalination}

- Problem/Need. Water utilities need a practical and comprehensive desalination technology guidance document. Ideally the document will address a full range of both technical considerations (e.g., technology selection, facility operation, concentrate management) and institutional considerations (e.g., permitting, financing, public acceptance). For both seawater and brackish desalination the guidelines must outline current regulatory requirements of different states.

- Objective. Desalination guidelines will help utilities identify the steps needed to successfully implement a desalination facility. Guidelines will also allow utilities to use consistent approaches in planning and implementing desalination. This, together with regulator involvement and buy-in to development of the guidelines, will help facilitate regulatory review and approval of desalination projects. A consistent approach to desalination planning will also help avoid missteps and oversights in the planning process, leading to reduced cost.

- Approach. Develop guidelines that address technical and institutional aspects of implementing desalination. 


\subsection{Research Agenda: Understanding the Economics of DESALINATION}

The site-specificity of desalination facilities makes it difficult to predict the economics of a given project. To alleviate this, a common basis for costing desalination plants must be developed so that accurate cross-comparisons can be made.

\section{Research Project: Common Basis for Costing Desalination}

- Problem/Need. Many agencies and organizations are being asked to provide funding for desalination projects. A common basis for the cost of desalination would be beneficial in providing a comparison of desalination costs against each other and against other alternative sources. Currently, reported costs vary due to different methods of calculating the capital, operating, maintenance, and finance costs. In many cases, reported costs include subsidies that are not explicitly reported.

- Objective. Develop a procedure to identify desalination capital and operation and maintenance costs so that a standardized comparison can be made between different desalination plants around the world. The model will include brackish and seawater desalination costs for thermal and membrane technologies.

- Approach. (1) Develop/validate a documented process for using a normalized spreadsheet-based desalination cost model that will be available to the water supply community. The model will assist in the initial decision making process when looking at alternative sources of water supply. (2) Compare the costs of existing desalination projects around the world. The expectation is that this comparison would reveal where differences in costing have occurred as well as provide a normalized cost comparison of the plants.

\section{Research Project: Inventory of Desalination Water Costs for Various Applications}

- Problem/Need. Desalination and blending of water provides an opportunity to produce different qualities of water for different consumers. A desalination inventory is an invaluable source of information for water managers, utilities, and planners.

- Objective. Provide an inventory of capital and operations and maintenance (O\&M) costs for different qualities of product water for use by utilities and planners.

- Approach. Compile information for capital and O\&M costs of producing desalinated water.

\subsection{Research Agenda: Consumer Outreach}

Consumers create the market. By gaining a better understanding of consumer attitudes toward desalination, educational materials can be better targeted.

\section{Research Project: Consumer Understanding, Attitudes, and Surveys}

- Problem/Need. In order to better establish consumer attitudes and understanding of desalination a survey (or series of surveys) should be conducted. Acceptability of desalinated water could be greatly enhanced by improving understanding of the advantages of desalinated water and the various uses of the product water.

- Objective. Conduct survey, and then use the results to establish follow-on actions to strengthen consumer understanding. 
- Approach. Conduct a representative survey of a cross-section of consumers across different income brackets, geography, and end-user profiles.

\subsection{Research Agenda: Determine Benefits of Desalination}

Desalination plants tend to be viewed in isolation apart from other water planning activities. To emphasize the contribution of desalination to the global water picture, a model (or models) should be built that better communicates the benefits and potential impacts of desalination plants.

Research Project: Multi-Scale (Local, Regional, State, National) Benefits and Impacts

- Problem/Need. Current desalination proposals focus simply on supply needs as opposed to a more comprehensive perspective that takes into account resource and geographic factors. Rather than just local cost and benefits, broader values must be applied that consider an integrated water resources management approach. This will help the state or local region achieve a balanced and diversified water portfolio.

- Objective. Develop a model for water and land use planners that integrates individual projects into regional desalination and water management plans and which includes water conservation, water recycling, water transfer or any water development options.

- Approach. Identify parameters; collect data; develop/verify model and implement.

\subsection{Research Agenda: Synthesize State of the Science}

At present, the state of the science of desalination is widely dispersed and compartmentalized. To improve the understanding of desalination and facilitate cooperation and collaboration amongst entities involved with desalination, a compendium of existing information should be created.

\section{Research Project: Synthesis of State-of-the-Science of Desalination in the United} States

- Problem/Need. The water community needs a "one-stop shopping" compendium of desalination information. A database, similar to the National Database of Water Reuse Facilities, might be developed. Other documents on desalination such as the recent one by the Pacific Institute could to be incorporated. The United Nations Educational Scientific and Cultural Organization's efforts to develop an inventory, guidelines, and state of the- cience in desalination should be incorporated as well. Having such a compendium/database would improve understanding of desalination and facilitate cooperation and collaboration during development of desalination projects by providing information on similar projects that use similar technologies.

- Objective. Develop a compendium/database of information on desalination.

- Approach. Select and procure contractor; conceptualize database and decide on information needs; select software, design database, conduct initial data collection, and start beta testing; populate the database; launch the database and decide on how to respond to various types of queries from users. 


\section{APPENDIX A: MEETING PARTICIPANTS}

\section{A1. Stakeholders Meeting}

Edmund Archuleta
Thomas Arn
Jorge Arroyo
Robert Bastian
Patrick Brady
Shahid Chaudhry
Joseph Cotruvo
Mike Gabaldon
Ken Herd
Tom Hinkebein
Fawzi Karajeh
Rick Karlin
Hari Krishna
Ron Linsky
Bobby Lue
Chuck Martz
G. Wade Miller
Kevin Price
Phil Rolchigo
Steve Rossi
R. Rhodes Trussell

El Paso (TX) Water Utility

Red Oak Consulting

Texas Water Development Board

U.S. Environmental Protection Agency

Sandia National Laboratories

California Energy Commission

Joseph Cotruvo \& Associates

U.S. Bureau of Reclamation

Tampa Bay Water

Sandia National Laboratories

California Department of Water Resources

American Water Works Association Research Foundation

Texas Water Development Board

National Water Research Institute

Southwest Florida Water Management District

The Dow Chemical Company

WateReuse Foundation

U.S. Bureau of Reclamation

GE Infrastructure Water Process Technologies

City of Phoenix

Trussell Technologies, Inc.

\section{A2. Source Waters/User Needs Meeting}

Edmund Archuleta
Thomas Arn
Jorge Arroyo
Maryanne Bach
Robert Bastian
Patrick Brady
Elizabeth Burton
Neil Callahan
Sue Collins
Jay Dusenbury
Mike Gritzuk
Lisa Henthorne
Fawzi Karajeh
Promod P. Kulkarni
Mike Mickley
G. Wade Miller
David Moll
David Moore
Donald Polmann
Kevin Price
Chris Rayburn
Phil Rolchigo
Mike Sale
Nikolay Voutchkov

El Paso (TX) Water Utility

Red Oak Consulting

Texas Water Development Board

U.S. Bureau of Reclamation

U.S. Environmental Protection Agency

Sandia National Laboratories

Lawrence Livermore National Laboratory

R.W. Beck (Tampa Bay Water)

Sandia National Laboratories

U.S. Army, TARDEC

Formerly, Dir. of the Water Services Dept., City of Phoenix, AZ CH2M HILL

California Department of Water Resources

California Energy Commission

Mickley \& Associates

WateReuse Foundation

The Dow Chemical Company

Southwest Florida Water Management District

Tampa Bay Water

U.S. Bureau of Reclamation

Awwa Research Foundation

GE Infrastructure Water Process Technologies

Oak Ridge National Laboratory

Poseidon Resources Corporation 


\title{
A3. The Water InNOVATION Symposium
}

The following individuals attended all three Symposium workgroups:

Patrick Brady

Tom Hinkebein

G. Wade Miller

Kevin Price

Chris Rayburn

\author{
Sandia National Laboratories \\ Sandia National Laboratories \\ WateReuse Foundation \\ U.S. Bureau of Reclamation \\ American Water Works Association Research Foundation
}

\author{
A3.1. Membrane Technologies Workgroup \\ Robert Bastian \\ Elizabeth Burton \\ Neil Callahan \\ Shahid Chaudhry \\ Robert Currier \\ Joshua Dickenson \\ Jon Dietrich \\ Zachary Dorsey \\ Jörg E. Drewes \\ Jay Dusenbury \\ Isabel Escobar \\ Val Frenkel \\ David H. Furukawa \\ Chuck Hennig \\ Daniel Hsu \\ Fawzi Karajeh \\ Djanette Khiari \\ Hari Krishna \\ William A. Lovins III \\ Jim Lozier \\ David Moll \\ Bryan Pivovar \\ Donald Polmann \\ Tony Rachwal \\ Phil Rolchigo \\ Paul Shoenberger \\ Pick Talley \\ R. Rhodes Trussell, P.E. \\ Nikolay Voutchkov \\ Mark Wilf \\ Tae Yun \\ U.S. Environmental Protection Agency \\ Lawrence Livermore National Laboratory \\ R.W. Beck \\ California Energy Commission \\ Los Alamos National Laboratory \\ WateReuse Foundation \\ Reiss Environmental, Inc. \\ WateReuse Foundation \\ Colorado School of Mines \\ U.S. Army, TARDEC \\ University of Toledo \\ Kennedy/Jenks Consultants \\ Separation Consultants, Inc. \\ U.S. Bureau of Reclamation \\ U.S. Bureau of Reclamation \\ CA Dept. of Water Resources, Office of Water Use Efficiency \\ American Water Works Association Research Foundation \\ Texas Water Development Board \\ Boyle Engineering Corporation \\ CH2M HILL \\ The Dow Chemical Company \\ Los Alamos National Laboratory \\ Tampa Bay Water \\ Thames Water Research \& Technology \\ GE Infrastructure Water Process Technologies \\ West and Central Basin Municipal Water Districts \\ Pinellas County Utilities \\ Trussell Technologies, Inc. \\ Poseidon Resources Corporation \\ Metropolitan Water District of Southern California \\ Metropolitan Water District of Southern California
}

\section{A3.2. Alternative Technologies Workgroup}

Robert Bastian

Neil Callahan

Shahid Chaudhry

Robert Currier

Joshua Dickenson

Zachary Dorsey

Jörg E. Drewes

Jay Dusenbury

Menachem Elimelech

David H. Furukawa
U.S. Environmental Protection Agency

R.W. Beck

California Energy Commission

Los Alamos National Laboratory

WateReuse Foundation

WateReuse Foundation

Colorado School of Mines

U.S. Army, TARDEC

Yale University

Separation Consultants, Inc. 
Christopher Gabelich

Daniel Hsu

Fawzi Karajeh

Djanette Khiari

Robert Krueger

Bruce Macler

Richard Martin

Tom Mayer

David Moll

John Pellegrino

Tommy Phelps

Donald Polmann

Tony Rachwal

Phil Rolchigo

Pick Talley

R. Rhodes Trussell

Jose Vergara

Nikolay Voutchkov
Metropolitan Water District of Southern California

U.S. Bureau of Reclamation

CA Dept. of Water Resources, Office of Water Use Efficiency

American Water Works Association Research Foundation

FilmTec Corporation

U.S. Environmental Protection Agency, Region IX

U.S. Bureau of Reclamation

Sandia National Laboratories

The Dow Chemical Company

University of Colorado at Boulder

Oak Ridge National Laboratory

Tampa Bay Water

Thames Water Research \& Technology

GE Infrastructure Water Process Technologies

Pinellas County Utilities

Trussell Technologies, Inc.

Metropolitan Water District of Southern California

Poseidon Resources Corporation

\section{A3.3. Concentrate Management Workgroup}

\author{
Robert Bastian \\ Kay Birdsell \\ Mark Buehler \\ Elizabeth Burton \\ Joshua Dickenson \\ Kelly DiNatale \\ Zachary Dorsey \\ David H. Furukawa \\ Christopher Gabelich \\ Michael Goff \\ Steve Hanson \\ Daniel Hsu \\ Scott Irvine \\ Jim Jordahl \\ Robert Krueger \\ Erin Mackey \\ Bruce Macler \\ Richard Martin \\ Nancy McTigue \\ Jean-Philippe Nicot \\ Donald Polmann \\ Tony Rachwal \\ Alan E. Rimer \\ William J. Steele \\ Anthony J. Tarquin \\ R. Shane Trussell \\ Jose Vergara \\ Jennifer Warner
}

U.S. Environmental Protection Agency

Los Alamos National Laboratory

Coachella Valley Water District

Lawrence Livermore National Laboratory

WateReuse Foundation

CDM

WateReuse Foundation

Separation Consultants, Inc.

Metropolitan Water District of Southern California

Southern Nevada Water Authority

Los Alamos National Laboratory

U.S. Bureau of Reclamation

U.S. Bureau of Reclamation

CH2M HILL

FilmTec Corporation

Carollo Engineers

U.S. Environmental Protection Agency, Region IX

U.S. Bureau of Reclamation

Environmental Engineering and Technology Inc.

University of Texas at Austin

Tampa Bay Water

Thames Water Research \& Technology

Black \& Veatch

U.S. Bureau of Reclamation

University of Texas at El Paso

Trussell Technologies, Inc.

Metropolitan Water District of Southern California

American Water Works Association Research Foundation 


\section{A4. THE INSTITUTIONAL ISSUES WORKSHOP}

Ashie Akpoji

Edmund Archuleta

Jorge Arroyo

Brian J. Armstrong

Tom Arn

Robert Bastian

Tony Bennett

Patrick V. Brady

Elizabeth Burton

Zachary Dorsey

Conner Everts

Kaya Freeman

Michael Gabaldon

Brent Haddad

Tom Hinkebein

Fawzi Karajeh

Phil Lauri

Doris Lovato

Sean McFarland

Darryl Miller

G. Wade Miller

Hy Pomerance

Kevin Price

Bob Raucher

Chris Rayburn

Robert Renner

Patrick Shields

Seth Snyder

Elizabeth Strange

R. Rhodes Trussell

Kent Turner

Erik Webb
South Florida Water Management District

El Paso Water Utilities - Public Service Board Membership

Texas Water Development Board

Southwest Florida Water Management District

Red Oak Consulting

U.S. Environmental Protection Agency

Texas Commission on Environmental Quality

Sandia National Laboratories

Lawrence Livermore National Laboratory

WateReuse Foundation

Southern California Watershed Alliance

Surfrider Foundation

U.S. Bureau of Reclamation

University of California - Santa Cruz

Sandia National Laboratories

CA Dept. of Water Resources, Office of Water Use Efficiency

Central and West Basin Municipal Water Districts

Awwa Research Foundation

City of Pompano Beach

Irvine Ranch Water District

WateReuse Foundation

Red Oak Consulting

U.S. Bureau of Reclamation

Stratus Consulting

Awwa Research Foundation

Awwa Research Foundation

Inland Empire Utilities Agency

Argonne National Laboratory

Stratus Consulting

Trussell Technologies, Inc.

California American Water Company

Office of Senator Pete Domenici 


\section{APPENDIX B: FINDINGS FROM THE SOURCE WATERS/USER NEEDS MEETING}

Attendees of the Source Waters/User Needs Meeting (convened May 2-3 in Tampa Bay, Florida) were charged to: "Elicit by source water a list of research needs to frame the direction and content of the Water Innovation Symposium meetings." During this meeting, they identified needs related to seawater desalination; to brackish water desalination; to the reuse of waters; and to cross-cutting areas such as energy consumption and monitoring technologies. Participants also identified a range of nontechnical issues that may inhibit the development/implementation of desalination and water purification technologies and approaches.

\section{B1. SeAwater}

The group members spent the majority of their time discussing challenges of RO based desalination of seawater, with only limited discussion of alternative seawater desalination. The group chose not to consider thermal desalination due to its unattractive economics when applied in the United States.

The seawater working group developed the following prioritized list of technology needs:

Applied Research to Address Near-Term Technology Needs

1. Pretreatment

2. Membrane performance and properties

3. Fouling

4. Energy

Basic Research to Address Long-Term Technology Needs

1. Non-RO research. Investigate alternatives for next-generation technologies to compete with RO in areas of energy consumption, cost, efficiency, robustness, etc.

2. Better understanding of fundamental of post-treatment problems, including
a. Disinfection
b. Stabilization
c. Blending

\section{Pretreatment}

Pretreatment of seawater is seen as a step in the RO process that could result in significant energy and cost savings, and result in more robust RO-based seawater desalination products. Within the pretreatment process step, breakout group members identified the following topics as needing basic or applied research:

- Assessment/monitoring of conditioning and performance of pretreatment

○ Monitoring of Assimilable Organic Carbon (AOC)

- Regeneration of cartridge filters

- Identification of impacts of alternatives (conventional vs. membrane pretreatment)

○ Dissolved air filtration 
- Sand filtration

- Accelerated sedimentation

- Chemical conditioning of source water-other oxidants, chemicals, fouling, wastewater disinfection

- Combining pretreatment and RO processes in one unit

- Designing to handle algal blooms, trace toxins

Advancing the state of the art in pretreatment will help to minimize the use of "consumables" (cartridge filters, chemicals, etc.) in RO desalination plants, thus lowering operating costs. Advances in pretreatment are also a component of creating more robust RO desalination systems that can accommodate and adapt to variations in source waters.

\section{Membrane Performance and Properties}

Improving the properties of membranes and increasing their performance is necessary to drive down costs and drive up reliability. Workgroup members identified the following as areas that warrant research and development activities:

- Better understanding of rejection capabilities of membranes for trace contaminants including

○ Boron

- Algae

- Pharmaceuticals and personal care products (PPCPs)

- Bromate/bromide

- Membranes with improved properties including

- Permeability

- Resistance to oxidants

- $\mathrm{pH}$ tolerance

○ Improved rejection and selective rejection

\section{Fouling}

Membrane fouling is a significant issue that drives up costs and reduces plant uptime due to increased maintenance and replacement. Workgroup members feel that basic research activities should be focused on

- Developing a better understanding of the fundamentals of RO fouling for the purpose of minimizing it.

- Gaining confidence that fouling can be controlled.

- Understanding the impact of organics and inorganics on fouling.

\section{Energy}

RO desalination is energy intensive. Workgroup members identified a need for applied research to improve the energy efficiency of the process, to better recover energy throughout the process, and to investigate the use of renewable energy sources.

\section{Non-RO Research}

Drawing upon their long experience in the desalination field, workgroup members identified several broad areas that offer the promise of leapfrogging the performance of current-generation technologies. These areas include:

- Capacitive deionization

- Evaporation technologies 
- Biotechnology as it can be applied to desalination

- Electromagnetics

- Advanced adsorbents (zeolites)

- Biomimetic systems

\section{Post-Treatment}

Workgroup members feel that the industry and regulators need to have a better understanding of the fundamentals of post-treatment issues including disinfection, stabilization, and blending. As desalination becomes a more important component of municipal and regional water supplies, a more complete and fundamental understanding of the problems presented by these activities is going to be necessary.

\section{B2. Brackish Waters (SuRfaCe AND Ground)}

The working group identified four primary User Needs areas:

1. Concentrate management

2. Pretreatment of source water

3. Source water characterization

4. Total dissolved solids (TDS) removal

a. Conventional

b. Novel

\section{Concentrate Management}

Improving concentrate management options is a necessity for communities located in inland regions where ocean disposal of the concentrate is impractical. In particular, working group members identified the need for improved concentrate management options that will:

- Reduce volumes. The less voluminous the concentrate stream, the less concentrate that must be disposed. Reducing the concentrate stream volume also offers the opportunity to recover a greater percentage of water that can then be beneficially reused.

- Reduce energy and other costs. Managing and/or disposing of concentrate streams is energy- and cost-intensive. Where practical, R\&D should be focused on reducing the energy consumption and cost of concentrate management approaches.

- Provide for beneficial use. Concentrate streams may contain elements that can be beneficially used in industrial processes, building materials, and a host of other applications. Research should be focused on identifying these beneficial use elements and creating cost-effective methods for removing them from the concentrate stream.

- Overcome/address current institutional barriers. The management and disposal of concentrate streams today is complicated by regulation, legislation, and other institutional barriers. These institutional barriers drive up the cost of concentrate management activities, and inhibit the introduction of desalination and water purification technologies. Research should be focused on supporting sciencebased regulation and legislation related to concentrate management. In particular, there is an interest in facilitating regulatory flexibility for subsurface disposal. 


\section{Pretreatment of Source Waters}

Improving the pretreatment of source waters offers significant benefits for owners and operators of inland desalination and water purification plants and their customers. Workgroup members recommend the following areas of R\&D focus:

- Improve membrane performance. Workgroup members would like to see membranes that are more effective at removing particular elements (in particular $\mathrm{Si}$ and $\mathrm{Ca}$ ), that are more resistant to biofouling, that reduce the use of antiscalants, and that offer better solids control.

- Reduce maintenance and replacement costs. Workgroup members identified cost reduction as an important area of research for pretreatment processes. In particular, they would like to see pretreatment processes that require less maintenance than today's technologies, and processes and technologies that are either cheaper to replace or that need to be replaced less often.

- Increase reliability. More reliable pretreatment systems will have a ripple effect throughout the subsequent desalination or purification processes. Increasing the reliability of pretreatment processes will reduce downstream problems like fouling or contamination, thus resulting in a more robust system.

\section{Source Water Characterization}

Many inland communities will soon face the prospect of utilizing non-traditional ground and surface waters. At present, the quality, quantity, and occurrence of these waters is poorly understood in many cases. To rectify this situation, workgroup members identified a need to develop a source water research characterization tool to

- Identify and quantify the occurrence of the resource.

- Provide a means to assess impacts of developing the resources on fresh groundwater resources.

- Establish the sustainability of the resource.

\section{Total Dissolved Solids Removal}

Brackish ground and surface waters exhibit TDS levels considerably lower than seawater; nonetheless, these solids must be removed. Because TDS removal from brackish waters is less challenging than that from seawater, the inland working group recommends "piggybacking" on the TDS removal work conducted for seawater desalination, but notes that they would like to see $R \& D$ in conventional membrane processes, alternative membrane processes, and non-membrane treatment methods.

\section{B3. REuse}

The Reuse working group was faced with the greatest challenges due to the large number of sources of water that communities may, in the future, wish to reuse. These include municipal wastewater (already being reused around the nation to water landscaping, for environmental restoration and preservation, and for myriad other non-consumptive uses); waters produced along with oil, gas, or coal extraction activities; industrial waste process waters; storm water; and agricultural return flows.

\section{Sensors/Monitoring}

The number and variety of contaminants found in reuse source waters present challenges not only to the technologist (who must devise methods for removing them and certifying 
their removal), but also for the water provider (who must convince the customer of its safety at any and every point in time). To meet these user needs, the working group recommends that basic and applied research be conducted in the following areas:

- In-line sensors capable of real-time assurance.

- Advanced real-time monitoring and control systems.

- Analytical methodologies and protocol development.

- Risk assessments to determine requisite removal levels for unregulated contaminants and to contribute to public education campaigns and perception.

\section{Contaminant Removal}

Removing contaminants from reuse source waters is complicated by the number and types of contaminants, variability in concentration and time, and changing regulations. Increasing the reuse of waters will require basic and applied research in the following areas:

- Removal/destruction of organics in combination with improved/reduced fouling of membrane-based, oxidative, thermal, and biological treatment processes.

- Removal of dissolved inorganic contaminants and materials, including metals, radioactive materials, emerging contaminants, and salinity reduction.

- Removal of suspended solids including biological entities (microbes, viruses), inorganics (colloids, etc.), and new emerging compounds (prions, etc.)

- Understanding the behavior of new materials (nanoparticles, weapons-of-mass destruction-type materials) and the characterization of their physical and chemical separations properties.

\section{Advanced Treatment}

As water reuse becomes more prevalent, more treatment options will come to market (demand will spur supply). In the meantime, working group members recommend research on advanced processes such as

- Biological treatment to include microbial optimization, bioaugmentation, environmental optimization, and community optimization.

\section{B4. Cross-Cutting Needs}

There are numerous technologies and processes available today to desalinate and/or purify water, and the diversity of these technologies and processes will only increase as research and development expand our understanding and knowledge.

Regardless of the technology or process (or combination of technologies and processes) chosen by the water provider, there are several cross-cutting needs that must be addressed through some combination of basic research and applied development work. These include:

\section{Energy}

Desalination and water purification processes tend to be energy intensive. Energy costs are a significant consideration for owners, especially in applications where consumers have become accustomed to functionally free water and in an environment of fluctuating energy costs. Meeting participants agree that the energy consumption of existing and new technologies must be addressed throughout the desalination and purification process from 
pretreatment to concentrate management and disposal activities. Participants singled out the following for R\&D activities:

- Reduction and Recovery. Energy is used (and wasted) throughout desalination and water purification processes. Participants see potential in developing or applying energy recovery devices, and in devoting time and resources to reducing the energy consumption of desalination- and water-purification-specific devices.

- Energy Sources. Participants suggested that owners consider the use of renewable or alternative energy sources when constructing desalination and water purification facilities. Garnering mention were solar electricity, geothermal, and wind energy.

\section{Monitoring/Measurement Technologies and Approaches}

Desalinated and/or purified waters are going to have to fight for acceptance, at least for the foreseeable future. To more rapidly gain public acceptance, it is vital that water providers be able to instantly and constantly monitor their processes and measure the quality of their product. This verification and assurance of quality will require the development of new technologies to monitor and evaluate the performance of membranes in real time and without inhibiting the performance of the plant. It will also require development of monitoring technologies and measurement protocols suitable for application in water reuse scenarios.

\section{Integrated Process Optimization}

Source waters/user needs meeting participants identified a need for holistic, system-wide design of desalination and water purification plants and processes. In particular, plants and processes should be optimized and integrated to minimize waste, recover byproducts, and minimize energy consumption. Additionally, sustainability (of the resource and the process) should be integrated into all process optimization, planning, and R\&D activities.

\section{B5. SUMMARY OF INSTITUTIONAL ISSUES Cost of Water/Value of Water}

Water is a low-cost commodity for most consumers in the United States; the reasons for this are varied and discussion and explanation of these reasons were beyond the mandate of the Source Waters/User Needs Meeting. However, participants were in agreement that consumers do not assign to water a realistic value; that is, their perceptions of the value of water is heavily influenced by the cost of water. The public misperception of "free" water negatively impacts the ability of utilities to build, operate, and sell desalinated or purified water-these products do not compete well (or at all, in some cases) on cost. To this end, participants call for a program to educate the general public on the true value and cost of water.

Industry and government partners also need to educate water providers about the economics of meeting new water quality standards either with existing technologies or with technologies that may be developed through the Roadmap Implementation process. Some current-generation technologies may not be able to meet new and evolving standards regardless of cost—-this signals the need for new treatment technologies. 


\section{Public Perception Part 1, Education}

Despite drinking bottled water purified by desalination and water purification technologies, the public, lawmakers, and regulators remain largely uninformed about these technologies and processes. They do not appreciate the quality of the water that can be produced, nor the relative cost of that water.

To educate the public and overcome some of the misperceptions about desalinated and purified waters, meeting participants call for development and execution of a coordinated strategy to inform local, state, and national leaders, opinion leaders, and the general public about the relative costs of these technologies, how they can benefit local and regional riverine and other aquatic environments (the environmental stewardship platform), and how they can be an important component of local and regional water supply portfolios.

\section{Public Perception Part 2, How to "Sell" Desalination and Water Purification Projects}

There is a growing need for desalination and water purification facilities in the United States; the causes of this growing need are detailed in the Roadmap, in publications from the National Academy of Sciences, in speeches and papers by prominent thought leaders like former Illinois Senator Paul Simon, and in articles in the Washington Post and the New York Times, among others.

The need for these facilities is growing slowly and silently ... there is unlikely to be a single catastrophic event that heralds a water shortage in the United States. Rather, it will be a decades-long combination of population growth and increased demand that will mandate the use of seawater, brackish water, and the reuse of impaired waters to meet demand.

The lack of a watershed event makes it difficult to "sell" desalination and water purification facilities to ratepayers and municipal governments. Participants discussed the following approaches to "sell" the technologies and processes:

- Selling in the short-term: Incentive-based strategies. Many locations across the United States face relative water shortages today. These locations have enough water for necessities, but not enough for activities such as unregulated lawn watering, car washing, etc. Some water providers have had success in increasing the use of reused waters by making it available for use in non-necessity applications like lawn and landscape watering and prohibiting the use of conventional domestic supplies in these applications.

- Quality vs. Availability. Some participants voiced the opinion that it might be easier to "sell" desalination and water purification plants on the basis of water quality rather than water availability.

- Total Water Management. In the United States, desalination and water purification technologies may be most easily "sold" as components of a total water management approach; as an augment to today's conventional water supplies, they facilitate the extension of those conventional water supplies while establishing the technology base necessary to ensure the supply of water as those 
conventional supplies become exhausted or as high-impact, low-frequency events cause sudden shortages (such as short-term droughts).

- Environmental Benefits. In many parts of the nation, environmental considerations limit the amount of water that can be drawn from conventional surface and subsurface sources. By touting the creation of "new" water, desalination and water purification projects can be sold as minimizing environmental impacts while maintaining quality of life for consumers.

- Regulatory Hedging. Investors hedge when they are uncertain about the future. Airlines hedge against rising fuel prices by buying next year's fuel at this year's prices. Water providers face increasing future costs as the number of regulated contaminants increases and removal levels become more stringent. Desalination and water purification technologies, due to their flexible design, offer water providers an opportunity to hedge against these future regulations - they can establish today the technological base to meet current and future challenges.

\section{Finance}

Desalination and water purification plants are expensive to build and operate. As such, the procurement and financing of these capital projects is a crucial element in the build/don't build decision making process. Participants would like to see the industry develop rigorous cost scenario models that show the true costs of these plants over time; they believe that constrictions of conventional water supplies will make the cost of desalinated or purified waters relatively more attractive in the future. Participants would also like to see alternative procurement pathways developed by government-industry partnerships to assure cost equity among a region's water users, and greater outreach to the financial community.

\section{Information Needs for Industry}

The national desalination and water purification enterprise is not particularly wellcoordinated. To overcome the impacts of imperfect knowledge, participants call for the development (and systematic updating) of a national survey of desalination facilities and creation and operation of a virtual clearinghouse of information (to provide a "one-stop shop" of data including research findings, reports of real-world performance, legislation and regulation, etc.). The American Water Works Association's DesalNet is an existing resource that can be used to meet the industry's information needs.

Participants would also like to see national-level guidance on desalination and water purification-related issues, in particular the classification of water qualities, appropriate and allowable disposal of concentrates, and allowable uses of impaired waters.

\section{Regulation/Legislation}

Participants identified a host of changes and modifications to state and federal regulations and legislation that would accelerate the deployment of desalination and water purification technologies. These include:

- Make it "easy" for oil/gas/coal companies to "re-label" produced waters as a potential source water for reuse.

- Standardize methodologies.

- Develop and implement a national desalination policy.

- Create consistent concentrate disposal guidelines. 
- Examine and propose solutions to current incongruities (e.g., differentiate between wastewater and concentrate).

- Modify or remove barriers to create regulatory support for, rather than obstruction of, the deployment of desalination and water purification technologies.

- Restructure water management jurisdictions to accommodate future water source vs. water use issues.

- Devise EPA-driven standard methods and rulemaking for high-salinity analysis (metals, etc.) 
This Page Intentionally Left Blank

B-10 


\section{Implementation of the National Desalination and Water Purification Technology Roadmap:}

Structuring and Directing the

Development of Water Supply Solutions

Sandia is a multiprogram laboratory operated by Sandia Corporation, a Lockheed Martin Company, for the United States Department of Energy's National Nuclear Security Administration under contract DE-AC04-94AL85000. SAND No. SAND2006-3729P

WATER
RESEARCH
OONOATION

